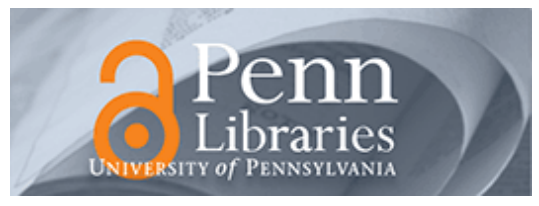

University of Pennsylvania

ScholarlyCommons

Real Estate Papers

Wharton Faculty Research

$7-2014$

\title{
Estimating the Distortionary Effects of Ethnic Quotas in Singapore Using Housing Transactions
}

Maisy Wong

University of Pennsylvania

Follow this and additional works at: https://repository.upenn.edu/real-estate_papers

Part of the Public Economics Commons, and the Real Estate Commons

\section{Recommended Citation}

Wong, M. (2014). Estimating the Distortionary Effects of Ethnic Quotas in Singapore Using Housing Transactions. Journal of Public Economics, 115 131-145. http://dx.doi.org/10.1016/

j.jpubeco.2014.04.006

This paper is posted at ScholarlyCommons. https://repository.upenn.edu/real-estate_papers/9

For more information, please contact repository@pobox.upenn.edu. 


\title{
Estimating the Distortionary Effects of Ethnic Quotas in Singapore Using Housing Transactions
}

\author{
Abstract \\ Desegregation is a key policy issue in many countries. I investigate a residential desegregation program in \\ Singapore - the ethnic housing quotas. I show that choice restrictions imposed on apartment blocks \\ above the quota limits (constrained) could have distortionary effects, causing price and quantity \\ differences for constrained versus unconstrained blocks. I test these predictions by hand-matching more \\ than 500,000 names in the phonebook to ethnicities, to calculate ethnic proportions at the apartment \\ block level. I can then investigate differences for constrained and unconstrained blocks close to the quota \\ limits and test for sorting around the limits. I find that price differences are between $3 \%$ and $5 \%$. Quantity \\ effects are economically significant, translating to longer time-on-market durations. Selection cannot fully \\ explain these results. My results point to challenges in achieving desegregation using quantity \\ restrictions.
}

\section{Keywords}

segregation, regulation, ethnic, quotas

\section{Disciplines}

Public Economics | Real Estate 


\title{
Estimating the Distortionary Effects of Ethnic Quotas in Singapore Using Housing Transactions
}

\author{
Maisy Wong $* \dagger$
}

October 22, 2013

\begin{abstract}
Desegregation is a key policy issue in many countries. I investigate a residential desegregation program in Singapore - the ethnic housing quotas. I show that choice restrictions imposed on apartment blocks above the quota limits (constrained) could have distortionary effects, causing price and quantity differences for constrained versus unconstrained blocks. I test these predictions by hand-matching more than 500,000 names in the phonebook to ethnicities, to calculate ethnic proportions at the apartment block level. I can then investigate differences for constrained and unconstrained blocks close to the quota limits and test for sorting around the limits. I find price differences are between 3\% and 5\%. Quantity effects are economically significant, translating to longer time-on-market durations by 1 to 1.4 months. Selection cannot fully explain these results. My results point to challenges in achieving desegregation using quantity restrictions.
\end{abstract}

*I wish to thank my advisers Professors Esther Duflo, Amy Finkelstein, Panle Jia and Bill Wheaton for guidance and support. I am also deeply indebted to Professors Peter Diamond, Fernando Ferreira, Michael Greenstone, Joe Gyourko, two anonymous referees and the editor for their helpful comments. I have benefited from conversations with Professor Chua Beng Huat, Jessica Cohen, Greg Fischer, Raymond Guiteras, Kam Lee Ching, Trang Nguyen and Wong Liang Kit. I would like to thank the Singapore Housing Development Board for permission to use their data. This study would not have been possible without support from the MIT Shultz Fund. I am also grateful for financial support from the Zell-Lurie Real Estate Center. Lee Hye Jin and Chen Ying provided excellent research assistance. All remaining errors are my own.

${ }^{\dagger}$ E-mail: maisy@wharton.upenn.edu; Address: 3620 Locust Walk, 1464 SHDH, Wharton Real Estate Department, University of Pennsylvania, Philadelphia PA 19104-6302. 


\section{Introduction}

Around the world, there are many policies encouraging gender and ethnic diversity in education, public and private employment, politics, and housing. ${ }^{1}$ Countries commit large amounts of money in their budgets to encourage diversity. ${ }^{2}$ In addition to these budget amounts, there could also be unintended distortionary costs introduced by these policies. There is a large literature on the redistributive benefits of these policies, but there is less on distortionary costs (Holzer and Neumark, 2000). I investigate potential policy-induced distortionary costs using a natural experiment in Singapore - the ethnic housing quota policy.

The quota policy was introduced in 1989 to prevent further segregation amongst the three major ethnic groups in Singapore - Chinese (77\%), Malays (14\%) and Indians (8\%) (Singapore Department of Statistics, 2000). The policy is a set of limits on Chinese, Malay and Indian proportions that determine which ethnic groups are "segregated" in an area. ${ }^{3}$ In areas above the quota limit, sellers from the non-segregated group cannot sell to buyers from the segregated group because this transaction increases the ethnic proportion of the segregated group farther above the quota limit. I quantify the distortionary effects of these policy restrictions by comparing housing transaction outcomes for constrained areas subject to the restrictions and comparable unconstrained areas. To my knowledge, this is the first paper to investigate distortionary effects of a residential desegregation policy using housing transactions. ${ }^{4}$

To do this, I develop a conceptual framework that delivers testable predictions on how prices and quantities are expected to differ for apartment blocks that are above the quota

\footnotetext{
${ }^{1}$ See Holzer and Neumark (2000) for a review of diversity policies in education, employment and government procurement in the United States. Around 100 countries have adopted gender quotas in politics (Krook, 2009). See Polikoff (1986) and Boustan (2011) for a review of residential desegregation policies. See Sowell (2004) for a survey of diversity-enhancing policies for other countries.

${ }^{2}$ In the United States, government procurement is estimated at 10\% of GDP and commonly includes preferential treatment to disadvantaged groups (Marion, 2009). In the European Union, large sums of money are dedicated to promoting a multiculturalism model of integration, including the European Integration Fund (US\$1 billion) and the European Social Fund (US\$92.3 billion). In Sweden and the Netherlands, the annual integration budget ranged from US\$615 million to US\$738 million.

${ }^{3}$ For example, if the percent of Chinese in an area is above the quota limit for Chinese, then, the Chinese are "segregated", as defined by the Chinese quota limit.

${ }^{4}$ There is a vast empirical literature on the causes and consequences of residential segregation (See, for example, Bayer, McMillan, and Rueben (2004); Card, Mas, and Rothstein (2008); Cutler, Glaeser, and Vigdor (1999); Gabriel and Rosenthal (1989)) but fewer studies of the impacts of residential desegregation policies (Banhardt, 2009; Boisjoly, Duncan, Kremer, Levy, and Eccles, 2006; Edin, Fredriksson, and Åslund, 2003; Rosenbaum, 1995). Edin, Fredriksson, and Åslund (2003) focuses on the redistributive benefits of a refugee placement policy in Sweden for refugees.
} 
limit (constrained) versus blocks below the quota limit (unconstrained). By restricting the choices of whom non-segregated sellers and segregated buyers can transact with, the model shows that these choice restrictions on the demand- and supply-side can lead to differences in transaction outcomes for constrained blocks versus unconstrained blocks.

The model has two important features: buyers have segregation preferences ${ }^{5}$ and housing markets are thin because housing attributes are heterogeneous along many dimensions (Arnott, 1989). Therefore, a housing unit in a given location with a vector of attributes could have few (or no) units sharing similar attributes. Because of segregation preferences, segregated buyers are willing-to-pay (WTP) more than non-segregated buyers to live in constrained blocks. So, non-segregated sellers who cannot sell to segregated buyers have to accept a lower price to attract non-segregated buyers. Because housing markets are thin, segregated buyers who can only buy from segregated sellers of constrained blocks, may be WTP a higher price to live in constrained blocks if their most preferred unit is in the constrained block, their second most preferred choice is in an unconstrained block and the two choices are imperfect substitutes.

In the paper, I show that under certain assumptions, the model predicts the following price and quantity effects. First, on average, prices will be higher for Chinese-constrained blocks versus comparable unconstrained blocks, but prices will be lower for Malay- and Indian-constrained blocks. Second, fewer units will be sold in constrained blocks versus comparable unconstrained blocks. The model also highlights two mechanisms that have opposite price effects (segregation preferences versus thin markets).

I test these predictions on prices and quantities using data on two transaction outcomes, prices and the proportion of units in an apartment block that was sold during my sample period. The main identification challenge is that whether a quota binds or not is correlated with unobserved housing quality. To circumvent the problem that quota-constrained and quota-unconstrained locations are not comparable, my strategy is to identify kinks in the outcome variable that coincide with kinks in the policy rule while controlling flexibly for ethnic proportions. The identification strategy is similar in spirit to the regression kink design (RKD). ${ }^{6}$

This research design requires many observations above and below the quota limits.

\footnotetext{
${ }^{5}$ Buyers have segregation preferences if they are willing-to-pay more to live in areas with a high proportion of own-ethnic-group members.

${ }^{6}$ For example, see Card, Lee, and Pei (2009)'s study on the impact of previous earnings (an endogenous running variable) on unemployment insurance benefits. Other examples include Saez (2010); Chetty et al. (2011). While the setup is very similar to regression discontinuity design (Angrist and Lavy, 1999; Hahn, Todd, and van der Klaauw, 2001), it does not fit within a standard regression discontinuity design (RDD) framework (Imbens and Lemieux, 2008; Lee and Lemieux, 2010) because the running variable of interest (ethnic proportions) is endogenous. To implement RDD, I would need pre-policy data on ethnic proportions. Unfortunately, I was not able to obtain it.
} 
However, many desegregation policies impose strict upper limits so that few or no housing areas are above these limits. ${ }^{7}$ By contrast, when the quota policy was implemented in Singapore in 1989, the Housing Development Board (HDB) did not want to evict owners in apartment blocks that were quota-constrained and they also wanted to minimize the number of households that would be affected. Therefore, they allowed all transactions that involved buyers and sellers of the same ethnicity because these transactions did not make housing areas more segregated. One benefit of analyzing housing transactions in my context is that there are many transactions both below and above the limits. ${ }^{8}$

This empirical strategy also needs data on the running variable used to determine the quota status. For the ethnic quotas in Singapore, the running variable of interest would be the ethnic proportions at the apartment block level. Since many of these policies are highly contentious, it is often hard to find public data of the running variable or even public data of the quota limits. ${ }^{9}$ I circumvent these data issues by hand-matching more than 500,000 names to ethnicities using the Singapore Residential Phonebook. This allows me to calculate ethnic proportions for more than 8000 apartment blocks. I combined this data with outcomes for more than 35,000 housing transactions that I downloaded from the HDB website. While I do not have administrative data used by HDB to determine the quota status of each block, I show in the paper that my proxy calculated using the phonebook is a valid measure of ethnic proportions.

An important identification assumption is that individuals cannot "precisely sort" around the quota limits so that variation in the treatment status around the policy limit is "as good as randomized" (Lee and Lemieux, 2010). I test for discontinuities in the density of the running variable and do not find evidence of sorting using Chinese and Indian proportions (McCrary, 2008). For Malays, the sorting pattern is not consistent with households trying

\footnotetext{
${ }^{7}$ For example, the VAMBAY housing program in Andhra Pradesh in India limit public housing clusters to be $75 \%$ Hindus and $25 \%$ Muslims. This means that clusters with more than $75 \%$ Hindus are unlikely to exist. Other countries, such as Germany and Denmark, also have strict quota limits.

${ }^{8}$ Bertrand, Hanna, and Mullainathan (2010) administered a survey to study the effect of affirmative action quotas in an Indian engineering college but "the strenuous data requirements of the regression discontinuity design methods coupled with (their) limited sample size reduced (their) ability to provide conclusive evidence on the returns to attending engineering school for the marginal admit" (p28).

${ }^{9}$ For example, McCrary (2007) estimates the impact of racial hiring quotas in municipal police departments in the United States using event study analysis because "information on quotas is much more poorly measured than whether a city was litigated, and the date the litigation began" (p349). Chay and Fairlie (1998) report that it is hard to identify the dates of adoption of a particular affirmative action program. Bertrand, Hanna, and Mullainathan (2010) point out the lack of datasets that comprise both the favored group who were admitted and the non-favored group who were not admitted due to affirmative action quotas in colleges. Marion (2009) studies the impact of procurement policies favoring disadvantage business enterprises but lacks data on which firms are owned by minorities. In a separate study, Marion (2011) looks at a subsample where he has data on minority ownership, but a weaker identification strategy.
} 
to manipulate treatment assignment. I return to this in the results section.

My estimates show price effects that are comparable to the literature on diversityenhancing policies and larger quantity effects. On average, transaction prices of Chineseconstrained units are 5\% higher than observably comparable unconstrained blocks. The average prices are 3\% lower for Malay- and Indian-constrained blocks. ${ }^{10}$ Additionally, I find that units in constrained blocks tend to be harder to sell. These effects are economically significant, translating into units being on the market 1 to 1.4 months longer (the median duration in this market is two months). ${ }^{11}$ I show that the results above cannot be fully explained by selection.

These estimated differences in prices and quantities between constrained and unconstrained blocks are consistent with my model. They suggest that choice distortions due to demand- and supply-side choice restrictions are significant, leading to differences in transaction outcomes. Further, I use the opposite price effects predicted in the model to disentangle the two mechanisms discussed above. I find evidence that segregation preferences are important for all three quotas. This suggests location preferences are inelastic because of segregation preferences. I also find support for supply-side constraints and thin markets for the Chinese quotas.

Together, these estimated policy effects on prices and quantities of sold housing units imply that transaction values of constrained blocks are $13 \%$ to $27 \%$ lower than the transaction values of comparable unconstrained blocks. My calculations suggest that more than $80 \%$ of the impact on transaction values is due to reductions in the quantity domain. Understanding these effects on transaction values is important because the ease of sale affects household mobility, housing transactions have spillover effects on the broader economy and housing transaction taxes are an important source of tax revenue. ${ }^{12}$

\footnotetext{
${ }^{10}$ Marion (2009) finds that removal of preference policies for minority-owned businesses led to $5.6 \%$ lower prices for state-funded government procurement, relative to the comparison group. Matsa and Miller (2013) find that gender quotas in Norwegian corporate boards had no effect on most corporate decisions but increased labor costs by $4.1 \%$ (as a share of assets) relative to control firms that were not affected by the quotas. The price effects are smaller, but of the same order of magnitude than price effects of other housing regulations. Autor, Palmer, and Pathak (2012) find that transaction prices for former rent controlled units increased by $6 \%$ to $8 \%$ following the removal of rent control in Cambridge. Wang (2011) finds a net increase in the equilibrium price of housing of $7.5 \%$, following the privatization of state-owned housing in China.

${ }^{11}$ Marion (2009) finds that the removal of affirmative action policies on state-funded procurement contracts did not affect the average number of bidders. Krasnokutskaya and Seim (2011) report that preferential treatment towards small firms in highway procurement bids lead to small changes in overall participation (approximately 1\%) but large heterogeneity on participation effects for small bidders (the favored group) versus large bidders.

${ }^{12}$ See, for example, Ferreira, Gyourko, and Tracy (2010); Mian, Rao, and Sufi (2013); Mian and Sufi (2011). Housing transaction taxes account for 10\% of tax revenue in Singapore in 2012 (Inland Revenue Authority of Singapore, 2013).
} 
These results point to distortionary effects from imposing quantity restrictions. An important lesson is that diversity-enhancing policies can exacerbate existing frictions, especially in the housing market. This contrasts against a literature on second-best choices suggesting distortions from diversity policies could offset existing imperfections in the market, leading to efficiency gains. ${ }^{13}$ It is exactly because the housing market is thin, there are already few transactions relative to the housing stock. Restricting non-segregated sellers from transacting with segregated buyers could exacerbate, rather than mitigate this problem, leading to even fewer units being sold for constrained blocks.

My findings have policy implications beyond Singapore. Many countries have residential desegregation programs, and some include quota limits. ${ }^{14}$ These results suggest it might take a long time to achieve desegregation goals. The fact that many blocks are still above the quota limits sixteen years after the policy was introduced, and that there are still meaningful differences in transaction outcomes between constrained and unconstrained blocks suggest the combination of inelastic preferences and thin markets is important, presenting challenges to achieve desegregation. In a separate paper that uses quasi-experimental variation from the quota policy to structurally estimate preferences and simulate the first best allocation of ethnic groups to neighborhoods, Wong (2013) finds that sixteen years after the policy, only $30 \%$ of neighborhoods are within one standard deviation of the first best allocation.

One caveat of the analysis is that I do not have pre-policy data so, I cannot simulate a counterfactual of no policy. My identification strategy compares transactions for constrained versus unconstrained blocks, holding the supply of housing units and the distribution of preferences fixed at the post-policy equilibrium. In the paper, I discuss possible confounders due to general equilibrium adjustments and show that they cannot fully explain my results. Moreover, the preceding discussion shows that finding meaningful differences in transaction outcomes for constrained versus unconstrained blocks so many years later is important.

The remainder of the paper proceeds as follows. In Section 2, I provide some background on Singapore and the ethnic quotas. I describe the data in Section 3, provide a theoretical and empirical framework in Sections 4 and 5, discuss results in Section 6 and

\footnotetext{
${ }^{13}$ See Holzer and Neumark (2000) for a review. See Corns and Schotter (1999) and McAfee and McMillan (1989) for examples of efficiency gains due to diversity-enhancing policies that encourage more competition in a setting with imperfect competition. Another example is affirmative action hiring and admission policies offsetting problems due to statistical discrimination and imperfect information.

${ }^{14}$ For example, there are religion-based quotas in a housing program in Andhra Pradesh in India, settlement policies in Germany, the United Kingdom, Sweden, Denmark and Israel have restrictions on where newly arrived immigrants can settle to reduce immigrant concentration (Scott, 2006; Banhardt, 2009; Dutch Refugee Council, 1999). There are also many "integration maintenance programs" or "neighborhood stabilization programs". See Polikoff (1986) and Boustan (2011) for an overview.
} 
conclude in Section 7.

\section{Background}

Singapore is a multi-ethnic country with a population of 4.5 million (Singapore Department of Statistics, 2006). The three major ethnic groups are the Chinese (77\%), the Malays (14\%) and the Indians (8\%). The Chinese have the highest median monthly income (S\$2335), followed by the Indians (S\$2167) and the Malays (S\$1790). Although the median Malay household is poorest, the income distribution of the Indians have a longer left tail (more Indians are very poor). Also, the ownership rate in public housing is the lowest amongst the Indians.

Public housing is the most popular choice of housing in Singapore with $82 \%$ of the resident population living in public housing (Housing Development Board, 2006). The units are built and managed by the Housing Development Board (HDB). Public housing was first built in Singapore in 1960 to solve the young nation's housing crisis (Parliamentary Debates, 1989).

There are three ways Singapore residents can live in an HDB unit. They may apply through the primary allocation system for new HDB units, ${ }^{15}$ they may purchase existing HDB units in the resale market or they may rent. The rental market is negligible (98\% percent of the HDB units are owner-occupied) because rentals are regulated to ensure that public housing is used for primary residences only (Housing Development Board, 2006). ${ }^{16}$ This paper focuses on the resale market only.

Public housing in Singapore is based on the concept of new towns: self-contained, large scale satellite housing developments that usually includes public housing units, a town center and a range of amenities. HDB dwellings are relatively uniform. To cater to the different needs of households, HDB designed and built 8 unit types. Type 1 is a studio, Type 2 is a 1-bedroom unit, Type 3 is a 2-bedroom unit. Types 4 to 6 all have 3 bedrooms, but the higher types have extra living and/or dining areas. The remainder 2 types are called

\footnotetext{
${ }^{15}$ All eligible Singapore citizens can apply to buy new HDB units in the primary market. To be eligible, the applicant must be married, aged 21 and above and have gross income below a ceiling determined by HDB for that year. The primary market comprises mostly new HDB units that are built-to-order in new HDB estates. Most applicants are first time buyers because applicants must not have interest in any other property within 30 months of the application. Applicants can submit a request for one of the 8 HDB types of units and also a preference for one of the $3 \mathrm{HDB}$ zones (North, North East and West). A computer ballot will determine the applicants' queue position to book a unit. Lottery winners are given 3 months to select a new unit. They will typically wait 2 to 3 years before the unit is completed in the new HDB estate. After 5 years, the owners are free to sell their units in the resale market.

${ }^{16}$ In my sample period, owners of public housing are only allowed to rent if they can prove that they need to be out of the country for an extended period.
} 
HUDC and multi-generation units. These tend to be larger units but HDB built very few of them. The most popular units are type 3 to 6 . Apart from the number of rooms, the layout and size in public housing units are relatively homogeneous.

To understand the ethnic quotas, it is important to understand the geography of housing markets in Singapore. The smallest spatial unit is an HDB unit. An HDB block is a multistoreyed apartment block with an average of 74 households. HDB neighborhoods are clusters of HDB blocks. The average neighborhood in Singapore has 4000 households, 45 HDB blocks and an average land area of 1.5 square miles. Due to the high population density in Singapore, a neighborhood is comparable to a US Census block group by land area but it is comparable to a US Census tract by population size. HDB towns are clusters of HDB neighborhoods.

Figure 1 shows a map of an HDB community with HDB blocks and HDB neighborhoods. HDB blocks and neighborhoods are terms used by HDB to describe clusters of public housing units. Throughout the paper, blocks and neighborhoods refer to HDB blocks and HDB neighborhoods. Each number in the map corresponds to an HDB block. Notice that the block numbers range from 100 to 600 . There are 4 HDB neighborhoods in the map. All blocks that range from 100 to 199 belong to neighborhood 1 and all blocks from 200 to 299 are in neighborhood 2 and neighborhoods 4 and 5 are defined similarly. HDB neighborhoods are clusters of HDB blocks that are spatially contained, and separated from other HDB neighborhoods and other private housing by main roads. All HDB blocks and neighborhoods include public housing units only. There are no private housing units in this map.

\section{Ethnic Integration Policy}

In late 1988 and early 1989, the government began to sound alarms about the growing "concentrations of racial groups" and the "gravity of this problem". They were concerned about going back to "the pre-1965 period when conditions bred distrust and misunderstanding among the various races and when there were even racial riots". The Minister for National Development pointed out as an example that in the town of Bedok, "if present trends continue, the proportion of Malays will reach $30 \%$ by 1991 , and will exceed $40 \%$ in 10 years' time". He was also concerned that "once a critical point is passed, racial groupings accelerate suddenly". In response to these trends, the government announced the Ethnic Integration Policy in a parliamentary debate on February 16, 1989 and the policy was implemented starting March 1, 1989 (Parliamentary Debates, 1989).

The policy is a set of quota limits at the block and neighborhood level. Table 1 lists the limits, in comparison to the 2000 national ethnic proportions. There are block level and neighborhood level limits. They chose the HDB neighborhood as the basic unit to apply the quota because "the neighborhood is a distinct entity with a well-defined physical 
boundary". Quota limits were set depending on the rate of formation of new households as well as recent trends in applications. At that time, applications for HDB units did not reflect the ethnic composition in Singapore. Chinese, Malays and Indians accounted for $74 \%, 19 \%$ and $7 \%$ respectively. The neighborhood limits allow some flexibility relative to these proportions. The Chinese neighborhood limit was set at $84 \%$ (10\% more than the share of Chinese applications), and the Malay and Indian neighborhood limits were $3 \%$ above these proportions (22\% and $10 \%$ respectively). Block quotas were $3 \%$ above each neighborhood limit to allow some blocks to be more segregated relative to the neighborhood limit. It was important to the government to have specific limits that would be applied to "all the ethnic groups in all areas". They reasoned that giving a range would mean that "the limit will vary from place to place and this can give rise to a lot of suspicion and misunderstanding". Since then, the quota limits have been fixed over time and are also fixed for all areas (Parliamentary Debates, 1989).

The quotas are limits on ethnic proportions that determine which HDB communities are segregated (as defined by these limits). Specifically, the block and neighborhood quota limits determine which ethnic group is "segregated" in an HDB block and neighborhood, respectively. For example, Table 1 shows that the Chinese neighborhood- and block-level quota limits are $84 \%$ and $87 \%$ respectively. If the block level proportion of Chinese is above $87 \%$, the Chinese are "segregated" for that block. If the neighborhood level proportion of Chinese is above $84 \%$, the Chinese are the segregated group for all blocks in that neighborhood. An HDB unit can be constrained if its block or its neighborhood is above the respective quota limits.

For blocks and neighborhoods above the quota limits, the policy rule is to ban all transactions that make already segregated blocks and neighborhoods from becoming more segregated. Specifically, sellers from the non-segregated group cannot sell to buyers from the segregated group because this increases the ethnic proportion of the segregated group farther above the limit. ${ }^{17}$ However, transactions involving buyers and sellers from the same ethnicity will always be allowed because this does not increase the ethnic proportion.

The policy restrictions were designed to avoid extremely segregated outcomes without affecting too many households. For example, it was emphasized many times in the parliamentary debate that "no HDB owner, whether he is Chinese, Malay or Indian will be requested to move from his present flat". Resale statistics at that time showed that most HDB owners who sold their flats sold to buyers of the same ethnic group. Since, the policy was designed to allow all transactions involving buyers and sellers of the same ethnicity,

\footnotetext{
${ }^{17}$ These restrictions are easily enforced because the identity cards of all Singaporeans report their ethnicity. Also, all resale transactions have to be approved by the HDB. One of the approval steps involves checking whether the transaction violates the ethnic housing quotas. An inter-ethnic married couple can choose to use either ethnicities of the spouses.
} 
they estimated that fewer than 1700 owners would be potentially affected by the policy. The government also did not anticipate great price effects and reasoned that "it is a small price we must be prepared to pay in order to ensure that we do build a cohesive, better integrated society in Singapore" (Parliamentary Debates, 1989).

The policy appears to have reduced the Malay and Indian proportions in some places. For example, Lum and Tien (2003) report that the town of Bedok and Yishun had 59\% and $24 \%$ Malays and Indians in 1988 but only 19\% and 11\% respectively by 1998 . The third town they looked at, Redhill, started with $87 \%$ Chinese before the policy and still had $84 \%$ Chinese by 1998. There have been calls to relax the restrictions of the quota, especially when the "volume of transactions is actually very low and therefore the ability to sell the flat to the right ethnic group would be more difficult". There were also complaints that the policy "is posing a serious financial problem to some families" (Parliamentary Debates, 2003).

In spite of these complaints, the government has repeatedly insisted on maintaining the quota limits. In fact, the policy was even extended to non-Malaysian permanent residents. Beginning in March 2010, HDB began to enforce neighborhood and block quota limits (5\% and $8 \%$ respectively) on the share of non-Malaysian permanent residents. Malaysian permanent residents are not subject to the quota due to their close cultural and historical similarities with Singaporeans (both countries are former British colonies and Singapore was part of Malaysia for a short period in the 1960s).

Residential desegregation is also not unique to Singapore, including the use of quotas (see Footnote 14 for more examples). In Europe, many settlement policies place limits on where newly arrived immigrants can settle, mostly in an effort to avoid the formation of enclaves. For example, in Germany and Denmark, this is achieved by placing limits on the number of refugees each municipality is obliged to provide dwellings for (Dutch Refugee Council, 1999; Glitz, 2012).

\section{Data}

Table 2 lists the summary statistics of the full dataset. The analysis only focuses on the public housing market which represents $82 \%$ of the citizens and permanent residents in Singapore. There are 8,007 blocks and 35,744 resale transactions. The Data Appendix includes more details on how the sample was created.

\section{Ethnic proportions}

The hardest data to obtain was the ethnic composition at the apartment block level because data on ethnic proportions at a fine geographic level are often not publicly available. To calculate ethnic proportions, I hand matched more than 500,000 names to ethnicities 
using the 2005 Singapore Residential Phonebook. It was published on April 1st 2005. Households can request for phone and address records to be unlisted at a charge of $\$ 20$ per annum plus a one-time administrative fee of $\$ 20$. One concern is that higher income groups are more likely to opt out. The sample size of the phonebook suggests that a majority of Singapore residents did not opt to be unlisted. The ethnic proportions calculated using the phonebook data are also similar to the national ethnic proportions, I did not detect a dramatically lower Chinese proportion (if higher income groups are more likely to be unlisted, then, I should find fewer Chinese names in the phonebook since the Chinese are the higher income group). Higher income groups are more likely to be in private housing rather than public housing and it is unlikely that this omitted household characteristic is different for constrained and unconstrained units. These suggest that any selection effects due to phone listing behavior is likely to be small and not different by ethnic groups.

There are 549,133 listings that correspond to HDB blocks in the Ethnic Integration Policy. I was able to match 548,024 names to ethnicities (a 99.8\% match) using differences in the structure of Chinese, Malay and Indian names. For example, most Chinese names only have 2 or 3 words; Malay names are primarily Muslim names since $99 \%$ of Malays in Singapore are Muslims (Singapore Department of Statistics, 2000); Indian names are matched according to popular first and last names. Nevertheless, 1,109 names remain unmatched. Three listings were firms and 819 listings had names that only included initials or first names only and 287 listings had names with unidentifiable ethnicities (usually because I could not determine whether the names were Indian or Malay names). I dropped these unmatched names when constructing ethnic proportions (ie. the percent of Chinese in a block is calculated as the number of names matched as Chinese divided by the number of names in the block that were matched to Chinese, Malay or Indian). I also tried not dropping these 1,109 names and the results are similar.

The match between names and ethnicity is likely to be most accurate for Chinese names because of distinct last names. ${ }^{18}$ On the other hand, Indian and Malay proportions may be more prone to measurement error because many Indian Muslims adopt Arabic names that are very similar to Malay names. Of the matched listings, 459,192 were matched using popular first and last names. Many Chinese names were matched this way. $84 \%$ of these names were identified as Chinese names, $13 \%$ were Malay names and 3\% were Indian names. Another 88,832 names were matched individually. 50\% of these names were identified as Chinese names, $17 \%$ as Malay names and $34 \%$ as Indian names. Overall, the ethnic proportions calculated using the phonebook were $78 \%$ Chinese, $14 \%$ Malay and $8 \%$ Indian, very close to the national proportions reported in the 2000 Census (77\% Chinese, $14 \%$ Malay and $8 \%$ Indian).

\footnotetext{
${ }^{18}$ Even Chinese Muslims would tend to keep their Chinese last names.
} 


\section{Proportion of unit types}

I purchased a non-public dataset from HDB that is the census of all HDB blocks in Singapore. The dataset includes the number of each of the eight unit types in each block, the street address and the HDB town. I use this dataset to create eight measures of the stock of HDB supply, measured as the proportion of units in an HDB block that is of each of the eight types.

\section{Resale transactions}

Every three months, HDB would upload resale transaction data for the past three months on their website. They publish data on the type of unit sold, the square footage of the apartment unit, the year the HDB block was built, which floor range the unit is in (eg. between floors one and five, floors six and ten), price and month of sale, street address and block number. I calculate the age of the HDB block as 2006 minus the year it was built. The final sample includes 35,744 transactions between April 2005 and August 2006.

\section{Quota status}

Each month, HDB publishes the quota status of all the HDB blocks in the Ethnic Integration Policy on their website. I downloaded these quota dummies every month from March 2005 to July 2006. In total, I have 133,378 block-months. The website only indicates whether an HDB block is constrained but does not specify whether it is because the block or neighborhood quota limit was constrained in that month. If all blocks in a neighborhood are constrained, I know the neighborhood limit is binding. ${ }^{19}$ The quota data was missing for 117 block-months. See the Data Appendix for details on how I filled in the data for these 117 observations.

I matched the quota status of the previous month to each transaction so that the quota status of block $b$ in November 2005 is matched to the transaction price for units in the same block in December $2005 .^{20}$

\section{Stayers and movers}

I do not have data on seller ethnicity, but I do collect data on the ethnicity of stayers and movers in an HDB block by matching names and postal codes using the 2005 and 2006 phonebooks. Each phonebook includes six-digit postal codes that uniquely identify an HDB block. I am not able to identify addresses within an HDB block. I define stayers as households living in the same postal codes in 2005 and 2006. Movers are households who changed their postal code from 2005 to 2006. Entrants are phonebook listings that only appeared in the 2006 phonebook only. I provide more details in Section 2 in the data appendix.

\footnotetext{
${ }^{19}$ Neighborhoods are identified using the first two digits and the fourth digit of the postal code obtained in the phonebook.

${ }^{20}$ I repeated the analysis with a 3-month lag, instead of a 1-month lag and the main results are similar.
} 


\section{Conceptual framework}

My empirical analysis compares transactions in constrained and unconstrained blocks. This section lays out a theoretical framework to deliver testable predictions for two transaction outcomes: number of sold units (quantity) and prices. I focus on describing treatment effects for the Chinese block quota limits only. The effects for the other quotas are similar.

I use a static, discrete choice framework with heterogeneous households choosing heterogeneous HDB units. ${ }^{21}$ Each HDB unit $i$ is a bundle of attributes, $X_{i}$, including the number of rooms, paint color, amenities and price $\left(P_{i}\right)$.

Demand is driven by households who have heterogeneous preferences over these attributes. There are two types of households: Chinese (C) and non-Chinese (NC). Each household $h$ from ethnic group $g$ chooses an HDB unit $i$ to maximize his indirect utility:

$$
V^{h g}=\max _{i} V\left(X_{i}, P_{i} ; \beta^{h g}, y^{h g}, \varepsilon_{i}^{h g}\right)
$$

where $\varepsilon_{i}^{h g}$ is an idiosyncratic taste shock, $y^{h g}$ is income and $\beta^{h g}$ is a taste parameter that indexes the household's preference over housing attributes, drawn from two distributions, $F^{C}$ and $F^{N C}$, for the Chinese and the non-Chinese respectively. The outside option for each household is not moving. Households have segregation preferences so that Chinese prefer to live in Chinese communities where there are more Chinese neighbors and more amenities and attributes preferred by Chinese. ${ }^{22}$ Non-Chinese prefer to live in non-Chinese communities.

The supply of HDB units is fixed. Sellers have an outside option of not moving, which determines their reservation value. Sellers are profit-maximizers where the profit is the transaction price minus the cost of selling (which includes agent fees, transaction taxes and other costs). Every owner of an HDB unit is a potential seller who will sell if the price for his unit, net of cost, is above his reservation value.

Housing markets are thin because housing attributes are heterogeneous along many dimensions (Arnott, 1989). Therefore, a housing unit in a given location with a vector of

\footnotetext{
${ }^{21}$ There is a large literature on sorting in housing markets (eg. Tiebout (1956), Benabou (1993) and Epple and Sieg (1997)). Location choice models that use a discrete choice framework builds on McFadden (1973, 1978), Berry (1994) and Berry, Levinsohn, and Pakes (1995). For examples of discrete choice models in the urban economics literature, see Quigley (1985), Nechyba and Strauss (1998), Bayer, Ferreira, and McMillan (2007) and Wong (2013).

${ }^{22}$ Examples of ethnic-specific amenities include kindergartens that teach ethnic languages, places of worship, community centers that set aside space for cultural events and activities for different ethnic groups (eg. Tai-chi for Chinese, sepak takraw courts for Malays and cricket fields for Indians). In a qualitative study of ethnic relations, Singaporeans indicated a preference for "special ethnic community places", suggesting that ethnic based taste for amenities could be important (Lai, 1995).
} 
attributes could have few (or no) units sharing similar attributes. Thin asset markets are often characterized by having few transactions relative to the stock. ${ }^{23}$

In equilibrium, buyers and sellers are optimizing and have no incentive to deviate from their choices. All buyers are utility-maximizing, given their preferences and the set of housing units in the market. All sellers are profit-maximizing. Now that I have described the demand- and supply-sides and the equilibrium concept, we are ready to analyze the treatment effects.

My approach is to consider the different types of transactions, motivated by the ethnicbased restrictions of the policy. Given the two ethnic groups, and the fact that each transaction involves a buyer and a seller, there are four types of transactions:

- Type 1: The seller is non-Chinese and the buyer is Chinese (banned for blocks with more than $87 \%$ Chinese)

- Type 2: The seller is non-Chinese and the buyer is non-Chinese

- Type 3: The seller is Chinese and the buyer is non-Chinese

- Type 4: The seller is Chinese and the buyer is Chinese

\section{Empirical predictions}

The thought experiment is to compare HDB resale transactions for constrained blocks with $88 \%$ Chinese against transactions of units in unconstrained blocks with $86 \%$ Chinese. ${ }^{24}$ Because of segregation preferences, the Chinese are willing-to-pay (WTP) more for units in the $86 \%$ and $88 \%$ blocks than the non-Chinese.

The key intuition is that the choice restrictions of the policy act as limits to arbitrage. If banned and allowed choices are different, the rules prevent restricted buyers and sellers of the constrained blocks from arbitraging away these differences for the constrained block. In equilibrium, with heterogeneous choices, prices and quantities will differ for constrained blocks (with arbitrage limits) versus unconstrained blocks (no arbitrage limits). Whether these arbitrage limits will lead to differences in transaction outcomes depends on how much heterogeneity exists (how different are restricted and unrestricted buyers' WTP; how different are units owned by restricted versus unrestricted sellers).

\footnotetext{
${ }^{23}$ For Singapore, Tu and Wong (2002) report that the volume of annual transactions in the resale market is $5 \%$ of the public housing stock. In a study of trading frictions in the market for aircrafts, Gavazza (2011), reports that only $5.8 \%$ of the total stock of aircrafts in his sample traded within 12 months.

${ }^{24}$ The empirical implementation deviates from this ideal thought experiment in several ways, due to data limitations (I do not observe the ethnic proportions HDB uses to implement the policy) and sample size issues (there are too few blocks with only $88 \%$ and $86 \%$ Chinese). I abstract from these issues for the moment and return to them when I discuss empirics.
} 
Without heterogeneity, there is nothing to arbitrage away in the first place. If banned and allowed choices are different, then, limits to arbitrage imposed on transactions for constrained blocks will translate into differences in transaction outcomes between constrained and unconstrained blocks.

The empirical predictions below show how we can use transaction outcomes to investigate the distortionary effects of the policy's restrictions. The idea is that the policy restricts choices, if choices are heterogeneous and arbitrage limits are imposed on constrained blocks, transaction outcomes will differ across constrained and unconstrained blocks. These policy-induced choice distortions are costly because restricted buyers and sellers are forced to imperfectly substitute from banned choices to allowed choices. The "imperfectness" of the substitutability will depend on how heterogeneous choices are.

There are two types of choice restrictions. First, non-segregated sellers are facing demand-side choice restrictions because they cannot sell to segregated buyers. These demand-side choice restrictions affect transaction outcomes because of segregation preferences amongst buyers (segregated buyers and non-segregated buyers have different WTP). Second, segregated buyers are facing supply-side choice restrictions because they cannot buy from non-segregated sellers of constrained blocks. Supply-side choice restrictions could affect transaction outcomes if housing markets are thin, so that the choice restrictions could matter on the margin when there are few (or no) choices with similar attributes. The model highlights these two mechanisms: (i) demand-side choice restrictions and segregation preferences versus (ii) supply-side choice restrictions and thin markets.

In my notation below, I use a superscript to denote the transaction type and a subscript to denote the block. Prices could differ by type for the $88 \%$ block because of the ethnicbased restrictions of the policy. For example, $P_{88}^{2}$ is the price for type 2 transactions in the $88 \%$ block. I assume there are no limits to arbitrage in the $86 \%$ block because it is unconstrained, so, there is only one price $\left(P_{86}\right)$. I develop five predictions on transaction outcomes that inform the empirical analysis later. I summarize these in Table 3.

E1: Prices for type 2 trades will be weakly lower in the constrained block than prices for the unconstrained block, $P_{88}^{2} \leq P_{86}$

Non-Chinese sellers in the $88 \%$ blocks cannot sell to Chinese buyers. So, they have to accept lower transaction prices, in order to attract non-Chinese buyers who would not have bought into the $88 \%$ blocks otherwise. This is an example of demand-side choice restrictions leading to lower prices because of segregation preferences.

Whether this is a strict or a weak inequality will depend on how segregated preferences are (how different the WTP distributions are). If the marginal non-Chinese buyer for the $88 \%$ block has a strictly lower WTP than the marginal buyer for the $86 \%$ block, then, $P_{88}^{2}<P_{86}$. Since I did not place many restrictions on the distributions of WTP, the Chinese and non-Chinese WTP distributions could overlap significantly, so it is possible that $P_{88}^{2}=$ 
$P_{86}$ (though segregation preferences makes this unlikely).

E2: Prices for type 2 and type 3 trades will be the same in the constrained block, $P_{88}^{2}=P_{88}^{3}$

Non-Chinese buyers of the $88 \%$ blocks are unrestricted, they can buy from both Chinese and non-Chinese sellers. Therefore, any price differences between type 2 and type 3 trades will be arbitraged away because there are no restrictions from the policy to limit non-Chinese buyers from arbitraging price differences across Chinese and non-Chinese sellers.

E3: Prices for type 4 trades will be weakly higher in the constrained block, $P_{88}^{4} \geq P_{86}$

Chinese buyers cannot buy from non-Chinese sellers of the $88 \%$ blocks. If markets are thin, there could be a wedge in the willingness-to-pay between the marginal Chinese buyer's most preferred unit (that happens to be in the $88 \%$ block) and the second most preferred unit (that happens to be in the $86 \%$ block). This is an example of supply-side choice restrictions leading to higher prices because of thin markets.

Intuitively, Chinese buyers who cannot buy from non-Chinese sellers in the $88 \%$ blocks are facing a supply-side constraint (they cannot buy $12 \%$ of the units in the $88 \%$ block). If markets are thick, this restriction should not have price effects because substitutes are available for the Chinese buyers. If markets are thin, this supply-side choice restriction could lead to higher prices. ${ }^{25}$ This price difference depends on how heterogeneous supply is. Specifically, it depends on the marginal Chinese buyer's elasticity of substitutability between units Chinese buyers cannot buy and other units Chinese buyers are allowed to buy.

At this point, it is useful to make two observations. First, demand-side choice restrictions on which buyers restricted sellers can sell to lead to lower prices for these sellers because of segregation preferences. Conversely, supply-side choice restrictions on which sellers restricted buyers can buy from lead to higher prices for these buyers because of thin markets. These opposite effects on prices mean that, on average, the price differences between constrained and unconstrained blocks are theoretically inconclusive. Importantly, the opposite price effects of the two mechanisms (demand-side constraints due to segregation preferences (E1) versus supply-side constraints due to thin markets (E3)) allow me to disentangle them, as I explain in the results section.

Second, there are at most two equilibrium prices for the $88 \%$ blocks and the main margin whereby these two prices differ is by buyer ethnicity. This is because, for the three

\footnotetext{
${ }^{25}$ On average, $11 \%$ of HDB blocks are Chinese-constrained and at most $13 \%$ of these units are owned by non-Chinese. This seems like a fairly small reduction in the stock but is potentially significant when compared to the share of the stock that trades annually (5\% according to Tu and Wong (2002)).
} 
types of trades allowed for the $88 \%$ block, once we condition on buyer ethnicity, seller ethnicity only varies between type 2 and type 3 trades and prices for these two types of trades are the same (E2). ${ }^{26}$ In other words, conditional on buyer ethnicity, if E2 holds, prices should not differ by seller ethnicity $\left(P_{88}^{2}=P_{88}^{3}\right)$. Therefore, we can denote the two equilibrium prices for the $88 \%$ blocks as $P_{88}^{C}$ to represent prices paid by Chinese buyers (type 4 trades) and $P_{88}^{N C}$ to represent prices paid by non-Chinese buyers (type 2 and type 3 trades). This simplifies the analysis for average prices and also informs further tests discussed in the results section.

Now that we have discussed the predictions on prices, conditional on knowing buyer and seller ethnicity, we are ready to discuss predictions for the two main outcomes: average prices and the number of units sold.

E4: Average prices will be weakly higher in the Chinese-constrained block, $\overline{P_{88}} \geq P_{86}$ (it will be weakly lower for Malay-and Indian-constrained blocks)

The average price for the $88 \%$ block will depend on the shares of each transaction type, $s_{b}^{t}$. Equation (2) is essentially a weighted average of negative price differences due to demand-side constraints (E1 and E2) and positive price differences due to supply-side constraints (E3). Therefore,

$$
\begin{gathered}
\overline{P_{88}}-P_{86} \\
=\left(\left(s_{88}^{2}+s_{88}^{3}\right) * P_{88}^{N C}+s_{88}^{4} P_{88}^{C}\right)-P_{86} \\
=\left(s_{88}^{2}+s_{88}^{3}\right) *\left(P_{88}^{N C}-P_{86}\right)+s_{88}^{4} *\left(P_{88}^{C}-P_{86}\right)
\end{gathered}
$$

The overall effect on the difference in average prices depends on the transaction shares and the magnitudes of these opposite price differences.

We can bound these transaction shares. Since type 2 transactions are the only transactions involving non-Chinese sellers for the $88 \%$ block, we know that $s_{88}^{2}$ is bounded above by $12 \%$. Since $P_{88}^{N C} \leq P_{88}^{C}$, Chinese sellers would prefer to sell to Chinese buyers than non-Chinese buyers. So, $s_{88}^{4} \geq s_{88}^{3}$. Therefore, it is likely that type 4 trades are the majority of the transactions for the $88 \%$ blocks. If magnitudes of price differences are not too different, then, the net effect on average prices is heavily weighted towards a positive effect on average prices because the Chinese are the majority buyers.

Notice that the opposite is true for Malay and Indian quotas. The main point is that the Chinese are the overwhelming majority of in the country. So, whichever transaction type that involves them will heavily weight the sign of the average price effect towards that price difference. For example, if we examine the Malay quota (the block quota limit is $25 \%$ ), Chinese buyers are a part of the non-Malay buyers (type 2 and type 3 trades), so the average price effect is weighted heavily by the negative price effect $\left(P_{26}^{N M}-P_{24}\right)$.

\footnotetext{
${ }^{26}$ For non-Chinese buyers, they can buy from both non-Chinese sellers (type 2) and Chinese sellers (type 3); but Chinese buyers can only buy from Chinese sellers (type 4).
} 
E5: The number of type 2 and type 3 trades are weakly lower and the number of type 4 trades are weakly higher for the constrained blocks

I assume the distribution of sellers' reservation values is the same for the $86 \%$ block and the $88 \%$ block. $^{27} \mathrm{~A}$ unit is sold if the transaction price (net of cost) is greater than a seller's reservation value. Then, E1 implies that weakly fewer non-Chinese sellers will sell in the $88 \%$ block compared to the $86 \%$ block. Similarly, weakly fewer Chinese sellers will sell to non-Chinese buyers because of E2. By E3, the number of type 4 trades are weakly higher. The overall effect on the total number of transactions is theoretically inconclusive. If price effects in E1 are larger than price effects in E3, and price elasticities are similar, then, the overall effect on the total number of units sold should be lower for constrained blocks.

In summary, we can investigate the distortionary effects of the policy because choice restrictions imposed on constrained blocks translate into differences in transaction outcomes between constrained and unconstrained blocks, as explained in E1 to E5.

\section{Caveats}

There are a few caveats to the framework above. A more general model could allow supply to change but the assumption of fixed supply is appropriate given my sample period (less than two years). ${ }^{28}$

An important weakness is I cannot estimate the treatment effect of introducing the quota policy because I do not have pre-policy data to estimate a counterfactual of no policy. Therefore, I can only estimate "partial equilibrium" treatment effects in a setting where the policy has already been introduced. My research design holds fixed the supply of HDB units and the distribution of buyers and sellers at the post policy equilibrium, and compares transactions of constrained versus unconstrained blocks.

This analysis ignores general equilibrium effects of the policy. For example, one effect of the policy is the reduction of very segregated neighborhoods. Therefore, the location choice sets for households before and after the policy are likely to be different. The current analysis ignores this adjustment margin because it holds fixed the supply of HDB units. Another treatment effect outside the scope of this study is the impact of the policy on

\footnotetext{
${ }^{27}$ I discuss the impact of the policy on sellers' reservation values in the results section.

${ }^{28}$ The supply of new units in the resale market is small during this time frame. New supply in the primary public housing market is likely to have less impact on prices in the resale market because households who participate in the primary market typically have to wait two to three years for a unit to be completed in the primary market. Also, income limits and other eligibility criteria suggest that many households who are eligible to buy in the resale market are not eligible to buy in the primary market (see Footnote 15 for more details). So, households who are potential buyers in the resale market are unlikely to be potential buyers in the primary market.
} 
changes in preferences towards other ethnic groups. By encouraging households of different ethnic groups to mix, these households' preferences could change over time (Boisjoly et al., 2006).

While a full general equilibrium analysis such as Epple, Romer, and Sieg (2001) is beyond the scope of this paper, I investigate how three long run adjustments in the supply and demand side might bias my partial equilibrium estimates: endogenous sorting of households within HDB resale markets, endogenous sorting of households out of resale markets and endogenous supply of HDB resale units. I discuss these threats to identification in the results section.

Finally, one would also like to say something about the deadweight loss and incidence of this policy, again, with the partial equilibrium caveats above. Let me first discuss effects on total surplus, then, discuss incidence.

There are two sources of deadweight loss due to the policy restrictions, one related to quantity effects and another due to price effects. The policy bans type 1 trades for the constrained blocks (non-Chinese sellers cannot sell to Chinese buyers who have higher WTP). If all non-Chinese sellers who would have sold to Chinese buyers in the counterfactual (no choice restrictions on constrained blocks) can sell to non-Chinese buyers at the same price, then, there would be no differences in prices and quantities between constrained and unconstrained blocks. However, if we see fewer units sold for constrained blocks versus unconstrained blocks (my proxy for the counterfactual), this suggests some trades that have positive surplus that would have occurred absent the policy did not occur due to the policy restrictions. Second, if we find that prices are lower then, this suggests allocative inefficiencies because some units are not sold to buyers with the highest WTP. In other words, there could be inefficiencies because the type 1 trades that are banned by the policy for constrained blocks either do not occur or are instead substituted by type 2 trades that transact at a lower price (they are sold to non-Chinese buyers with lower willingness-to-pay).

On incidence, we would expect that sellers of constrained units would bear much of the burden, especially the non-Chinese sellers because it is likely to be harder to sell (number of units sold is lower) or conditional on a sale, sell at a lower price. If we see evidence of price increases, then some Chinese buyers buying Chinese-constrained units might be hurt also because the quota restriction means they can only buy from Chinese sellers and market thinnes might lead to premiums for these units. 


\section{Empirical Framework}

The thought experiment in the theoretical framework compares constrained versus unconstrained blocks that are otherwise conceptually identical. My empirical framework operationalizes this thought experiment by comparing transaction outcomes of constrained versus unconstrained units, restricting the analysis to blocks close to the quota limits, controlling flexibly for polynomials of ethnic proportions (an important attribute that drives sorting behavior) and a set of observables that can explain much of the outcome variation in my data. I test for treatment effects of the policy on three sets of outcomes: lnprice, the type of unit sold and the proportion of units sold. I restrict my analysis to observations within $10 \%$ of the Chinese, Malay and Indian block quota limits respectively. In this section, I describe the equations for the Chinese quota. The empirical set up for the Malay and Indian quotas are similar.

I estimate three sets of equations. The key regressors in the first two equations are at the block-month level and the key regressor in the final equation is at the block level. The following two equations use the assignment dummy from the HDB website as the key independent variable. Equation (3) only controls for smooth functions of the running variable, while equation (4) controls for other observable characteristics:

$$
\begin{gathered}
y_{i b k t}=\alpha+\beta Q C_{b k, t-1}+\sum_{l=1}^{4} \phi_{l}\left(\text { percent }_{b k}-0.87\right)^{l}+\varepsilon_{i b k t} \\
y_{i b k t}=\alpha+\beta Q C_{b k, t-1}+\sum_{l=1}^{4} \phi_{l}\left(\text { percent }_{b k}-0.87\right)^{l} \\
+B_{b k} \delta+\tau_{t}+\omega_{k}+\varepsilon_{i b k t}
\end{gathered}
$$

where $y_{i b k t}$ is the outcome variable for transaction $i$ in block $b$, town $k$ and month $t$; $Q C_{b k, t-1}$ is a dummy for whether the Chinese quota was binding in the previous month, $\left(\text { percent } C_{b k}-0.87\right)^{l}$ are $l^{\text {th }}$ order polynomials of the Chinese proportion, centered around the block quota limit, $B_{b k}$ includes observables for the HDB block, including the age of the $H D B$ block and its squared, proportion of units in a block that is of each of the seven HDB types (type 1 is the omitted group); $\tau_{t}$ and $\omega_{k}$ are month-of-sale and town fixed effects. The standard errors in (3) are clustered at the block level and standard errors in (4) are clustered at the town level. ${ }^{29}$

\footnotetext{
${ }^{29}$ I also tried estimating ethnic proportions separately for constrained and unconstrained blocks. The coefficient estimates are similar but not significant for some specifications when standard errors are clustered. I report the estimates using separate polynomials in the appendix.
} 
The key parameter of interest is $\beta$, the difference in outcomes between observably comparable transactions in constrained versus unconstrained blocks. As discussed in E4 in the previous section, if the outcome is price, I expect $\beta$ to be positive for Chinese quotas and negative for Malay and Indian quotas.

The main challenge in interpreting $\beta$ as the treatment effect of the policy is omitted variables. For example, the price of constrained units could be higher than the price of unconstrained units (even if the true $\beta$ is zero) because areas with more unobserved Chinese amenities tend to attract more Chinese, so, are more likely to be Chinese-constrained and more expensive (the quota dummy is correlated with unobserved housing quality). Below, I test this identification assumption and argue that selection on unobservables cannot explain my treatment effect estimates.

The final equation is estimated at the block level because the outcome (the proportion of units in a block that is sold in the sample period) does not vary across time:

$$
y_{b k}=\alpha+\beta \text { percent } Q C_{b k}+\sum_{l=1}^{4} \phi_{l} \text { percent } C_{b k}^{l}+B_{b k} \delta+\omega_{k}+\varepsilon_{b k}
$$

where percent $Q C_{b k}$ is the proportion of months the Chinese quota is binding in the sample period. Here, $\beta$ estimates the impact of a percentage point increase in the proportion of months the quota is binding on the proportion of units in a block that is sold within the sample period. As discussed in E5, I expect $\beta$ to be negative. Here, the treatment effect is identified off of variation between blocks that are likely to be constrained within my sample period versus blocks that are less likely to be constrained.

My empirical framework is similar in spirit to the regression kink design (RKD) in Card, Lee, and Pei (2009). The strategy is to identify kinks in the outcome variable that coincide with kinks in the policy rule while controlling flexibly for the assignment variable used to determine the policy rule (ethnic proportions). The kink at the quota limit is key. The identification strategy relies on the step function of the quota status where units are unconstrained (the quota status is 0 ) below the quota limit on ethnic proportions and units are constrained (the quota status is 1) above the limit.

While the setup is very similar to regression discontinuity design (Angrist and Lavy, 1999; Hahn, Todd, and van der Klaauw, 2001), it does not fit within a standard regression discontinuity design (RDD) framework (Imbens and Lemieux, 2008; Lee and Lemieux, 2010) because the running variable of interest (ethnic proportions) is endogenous. Therefore, the identification strategy is more similar to Card, Lee, and Pei (2009)'s study on the impact of previous earnings (an endogenous running variable) on unemployment insurance benefits. They argue that even though workers can control their earnings, lack of information on the precise location of the kink-point can rule out extreme forms of sorting. 
The identification assumption is that all households are unable to precisely control treatment assignment around the threshold so that variation in the treatment assignment around the limit is as good as randomized. It is not a violation of the identification assumption if households can exert some control over the running variable as long as they do not precisely control on which side of the limit they land (Lee and Lemieux, 2010). It is hard for households to sort precisely around the quota limit because they do not know ethnic proportions. Moreover, HDB only reports monthly indicator variables of whether an apartment block is constrained but does not publish the history of each block's treatment status. So, households cannot see how frequently blocks are switching between the constrained and unconstrained status to infer how close blocks are to the quota limit.

There are several limitations to my empirical framework that are mostly data driven. First, the ideal running variable would be pre-policy ethnic proportions at the apartment block level. Since the policy was announced and implemented within 3 weeks, this would have been an ideal natural experiment because households would not be able to manipulate treatment assignment by sorting. For various reasons, data on ethnic proportions are not publicly available at the local level and I was not able to obtain the 1989 phonebook.

Absent the pre-policy data, the next best candidate would have been monthly administrative data on ethnic proportions that HDB uses to determine whether a block is quotaconstrained or not. Using names in annual phonebooks to proxy for monthly ethnic proportions introduces two sources of measurement error. First, names may not match perfectly to ethnicities. This measurement error should bias against estimating any discontinuities. Even if names are perfect measures of ethnicities, annual phonebooks miss the monthly variation so that the actual quota status could be constrained for some months even though the annual ethnic proportion is below the quota limit. Another approach would be to use switchers (apartment blocks that switch from constrained to unconstrained across months or vice versa) but there are too few switchers during my sample period. Below, I show that my proxy is a valid measure of ethnic proportions.

Finally, I have a limited set of observables. While the number of controls is small compared to other studies of housing markets, the observables I have can explain a similar amount of variation in prices as these studies because public housing in Singapore is less heterogeneous than private housing in the United States. I am able to explain up to $95 \%$ of the variation in prices by using just sale type dummies, block fixed effects and month-of-sale fixed effects. ${ }^{30}$ In my analysis, I control for location amenities using town and neighborhood fixed effects. HDB neighborhoods are comparable to US census block

\footnotetext{
${ }^{30}$ In Levitt and Syverson (2008), the most saturated regression specification explains $96 \%$ of the variation in house prices in Boston, using block fixed effects and a rich set of controls (including keywords in descriptions in the Multiple Listing Service). Using a similar dataset for the housing market in Wisconsin, Hendel, Nevo, and Ortalo-Magne (2009) can explain up to $93 \%$ of the variation in house prices.
} 
groups by area.

\section{Results}

In this section, I first describe the main results on transaction outcomes, then, discuss takeaway lessons from these estimates. The main take-away is that segregation preferences leads to worse market outcomes for constrained units, primarily through quantity effects. These point to distortionary costs because some sellers are restricted from selling to buyers of the higher WTP ethnic group. Together, my findings quantify the distortionary effects of imposing restrictions in the housing market to enhance diversity. Finally, I discuss major threats to identification of the treatment effects and argue that alternative stories cannot explain my results.

\subsection{Main results}

\section{Transaction Prices}

Table 4 reports statistically significant effects on prices for Chinese-, Malay- and Indian-constrained blocks versus comparable unconstrained blocks. Column 1 estimates equation (3) and only controls for polynomials of ethnic proportions. Column 2 adds controls on the age of the block and its squared, the proportion of each of the seven types of units (type 1 is the omitted group), town and month-of-sale fixed effects and column 3 adds town-by-month linear trends. My preferred specification for price effects (column 3) can explain $75 \%$ to $80 \%$ of the variation in prices.

On average, the transaction price for Chinese-constrained units is $5 \%$ higher than transactions in comparable unconstrained blocks. Conversely, the prices for Malay- and Indianconstrained units are 3\% lower. The signs of these effects are consistent with E4 in the theoretical framework. The size of these price differences represent 5 times the median monthly income of the Chinese (S\$2,335) and 3 times the median monthly income of the Malays $(\mathrm{S} \$ 1,790)$ and the Indians $(\mathrm{S} \$ 2,167) .{ }^{31}$

The magnitudes of the price effects are comparable to the literature. Marion (2009) finds that removal of affirmative-action type restrictions for highway construction contracts in California led to a 5.6\% decline in the cost of state-funded contracts (treatment group) relative to federally funded projects. Matsa and Miller (2013) report that the introduction of gender quotas in Norwegian corporate boards did not impact most corporate decisions, except employment. Relative labor costs as a share of assets increased by $4.1 \%$ for firms with gender quotas compared to the control group. My price effects are slightly

\footnotetext{
${ }^{31}$ Calculated using the average price of units sold $(\mathrm{S} \$ 234,000)$.
} 
smaller than estimated price effects of other types of housing regulation but of the same order of magnitude. Autor, Palmer, and Pathak (2012) find that transaction prices for former rent controlled units increased by $6 \%$ to $8 \%$ following the removal of rent control in Cambridge. Wang (2011) finds a net increase in the equilibrium price of housing of $7.5 \%$, following the privatization of state-owned housing in China.

As discussed in the theory, the policy affects transaction prices through two mechanisms: demand-side choice restrictions and segregation preferences versus supply-side choice restrictions and thin markets. Equation (2) shows that the differences in average prices estimated here are a weighted average of positive price differences (weighted by the share of Chinese buyers - type 4 transactions) and negative price differences (weighted by the share of non-Chinese buyers - type 2 and type 3 transactions), where the positive effects are due to supply-side choice restrictions and thin markets (E3) and the negative effects are due to demand-side choice restrictions and segregation preferences (E1). I use the opposite price effects of these two mechanisms to disentangle them.

The lower average prices for Malay and Indian quotas are consistent with demand-side choice restrictions and segregation preferences. When the non-segregated group (nonMalays and non-Indians) cannot sell to the segregated group (Malays and Indians), the restricted sellers have to accept lower transaction prices to attract buyers from the nonsegregated group who have a lower WTP. These lower prices point to costs that can arise due to allocative inefficiencies because the policy restricts some owners from selling to the buyer with the highest WTP.

By contrast, average prices are higher for transactions in Chinese-constrained blocks compared to transactions in unconstrained blocks close to the Chinese quota limit. I first show evidence that both mechanisms (lower prices due to demand-side choice restrictions and segregation preferences and higher prices due to supply-side choice restrictions and thin markets) underly these differences in average price. Then, I explain why the net effect is positive.

To test for the first mechanism (lower prices due to demand-side choice restrictions and segregation preferences), I interact the quota dummy in equation (3) with two proxies for non-Chinese buyers: a dummy for neighborhoods with above median shares of Malay movers and a dummy for neighborhoods with above median shares of Indian movers. ${ }^{32}$ The discussion above for equation (2) spells out that differences in average prices are a weighted average of positive and negative differences but the negative price differences

\footnotetext{
${ }^{32}$ As discussed in Section 3, I do not have data on the ethnicity of the buyer and seller. In the data appendix, I show how to use the ethnic distribution of movers (calculated using the phonebook) to proxy for the ethnic distribution of buyers. Since there are very few movers for each block, I cannot calculate this share at the block level because the shares are too noisy. I also control for these dummies for high mover shares separately, in addition to the interaction terms.
} 
increases with the share of non-Chinese buyers. Indeed, I find that the Chinese quota effect on average prices decreases as the share of movers who are Malay increases, consistent with Malay buyers having different preferences than Chinese buyers. I do not find this for Indian mover shares (the results are in Table A3 and more details are in Section 2 of the data appendix).

To test for the second mechanism (higher prices due to supply-side choice restrictions and thin markets), I investigate how treatment effects on average prices vary with the availability of housing substitutes in an HDB town. If the supply restriction matters for the marginal Chinese buyer, its effect on prices should be weaker if there are more substitutes available for the marginal Chinese buyer.

I expand my main treatment effect specification (equation (4)) to include an interaction of the Chinese quota dummy with the log of the (de-meaned) size of the housing stock in a town (my proxy for the availability of housing substitutes) and also controlling for the housing stock separately (this specification drops town fixed effects). My results indicate that in towns with a larger housing stock (more substitutes available), the positive premium is indeed smaller because more substitutes are available so the impact of the supply-side restriction on prices is weaker (the results are in Table A4 and more details are discussed in Section 3 of the data appendix).

The results from these two tests show that both mechanisms (E1 and E3) underly differences in average prices for Chinese-constrained blocks versus unconstrained blocks. But, the net effect on average prices is heavily weighted towards the effect due to supplyside choice restrictions (higher prices for constrained blocks) because the Chinese are the overwhelming majority of buyers. Using the phonebook data on the ethnic distribution of movers, I calculate that the share of movers moving into Chinese-constrained blocks who are Chinese is $74 \%$ (proxy of $s^{4}$ in equation (2)) and the share who are non-Chinese is $26 \%$ (proxy of $s^{2}+s^{3}$ ). Given these shares, the price decrease due to segregation preferences (E1) has to be almost 3 times as large as the price increase due to thin markets (E3), for the average prices to be lower for the constrained blocks compared to the unconstrained blocks. In other words, unless the marginal non-Chinese buyer moving into the constrained block really dislikes living in Chinese communities, the average price is likely to be weakly higher for the Chinese-constrained block.

In summary, the analysis above points to price effects due to demand-side choice restrictions and segregation preferences for all three quotas. ${ }^{33}$ There is also evidence that supply-side choice restrictions and market thinness leads to higher average prices for

\footnotetext{
${ }^{33}$ The effects on average prices are consistent with estimates of segregation preferences in the literature (Wong (2013); Bayer, Ferreira, and McMillan (2007)). Using the difference in WTP estimates between ethnic groups, I calculate that the implied differences in average prices between constrained and unconstrained blocks will be similar to the estimates in Table 4 .
} 
Chinese-constrained blocks. Next, I discuss robustness checks and the validity of the price effect estimates in Table 4.

Following Altonji, Elder, and Taber (2005) and Bellows and Miguel (2009), I calculate how large selection on unobservables would need to be to explain away the entire price difference. ${ }^{34}$ To do this, I divide my preferred estimate with controls (column 3 ) by the difference between the estimate without controls (column 1) and the estimate with controls. The larger the magnitude of this ratio, the more unlikely it is that the effect estimated is driven by selection on unobservables. The magnitude of the ratio is large if the effect to be explained away is large (the numerator) or if controlling for more observables does not change the estimate much (the denominator is small). In their paper, Altonji, Elder, and Taber (2005) report that a ratio of 3.55 would make selection on unobservables "highly unlikely" and a ratio of 1.43 would make it seem "unlikely". The ratio for the Chinese quota is $1.611^{35}$ and the ratio for the Malay (Indian) quota is 2.15 (-6.12). Therefore, it seems unlikely that selection of unobservables can explain the entire price effect.

The price effects fall to $3 \%,-0.7 \%$ and $-1 \%$ for Chinese, Malay and Indian quotas respectively when I control for neighborhood fixed effects instead of town fixed effects (column 4). Estimates with neighborhood fixed effects are identified from comparing constrained blocks versus unconstrained blocks within a neighborhood. The strength of these estimates are that they control for locational amenities for a small area (comparable to US census blocks). But, the weakness is that it is only identified off of neighborhoods that have within neighborhood variation in quota dummies. In my sample, more than half of the neighborhoods have no within neighborhood variation for Chinese and Malay quota dummies and more than a third of the neighborhoods have no within neighborhood variation for Indian quota dummies. For this reason, I report estimates for column 3 (town fixed effects) as my preferred specification. My main take-away is that price effects are still significant even controlling for neighborhood fixed effects. Furthermore, in Section 6.3, I discuss confounders to the estimates in column 3 (no neighborhood fixed effects) and argue that the price and quantity effects are most consistent with the model's predictions (choice restrictions affect transaction outcomes) while unobserved locational amenities alone cannot explain all the price and quantity effects.

Finally, column 5 adds block fixed effects (there are no controls because all the controls are time-invariant attributes at the block level). Identification is from time series variation in the quota status of a block. The coefficient estimates are insignificant because there

\footnotetext{
${ }^{34}$ Altonji, Elder, and Taber (2005) consider an empirical model with a bivariate normal structure while Bellows and Miguel (2009) develop the same test for a linear model that does not rely on the assumption of joint normality (this approach was also adopted by Nunn and Wantchekon (2011)). I adopt the latter approach because my estimation methods are closer to Bellows and Miguel (2009).

${ }^{35}$ Calculated using 0.050/(0.081-0.050).
} 
are too few blocks that switch quota status within my short sample period. The estimates using separate polynomials for constrained and unconstrained units are similar but there is less statistical power (see Appendix, Table A1). The main results are similar but are less robust for Indian quotas.

Figures $2 \mathrm{a}$ to $2 \mathrm{c}$ summarize these effects. The figures also show that price dispersion is larger for constrained units, consistent with segregation preferences. ${ }^{36}$ By limiting arbitrage, the ethnic-based restrictions of the policy allow equilibrium prices to differ by buyer ethnicity, leading to larger price dispersion for constrained units.

\section{Type of unit sold}

Table 5 reports estimates for equations (3) and (4), except the outcome is now the type of HDB unit sold. This regression tests for compositional differences in the types of units sold. ${ }^{37}$

The type of HDB unit is one of the most important attribute in public housing. The resale data published on HDB's website is organized by location and HDB unit type, presumably because many households search for comparables by unit type and location. A regression of lnprice on month-of-sale and neighborhood fixed effects explains $32 \%$ of the variation. Just adding dummies for the type of unit sold (from the resale data) increases the R-squared to $86 \%$. Higher types are more expensive. The coefficient on these type dummies are monotonically increasing with types and almost linear if we plot the coefficient estimates of the type dummies on the vertical axis and the type of unit sold on the horizontal axis. Therefore, I use an ordered probit specification where the dependent variable is an integer between one and eight, representing eight different types of HDB units.

\footnotetext{
${ }^{36}$ I did test whether the variance in price is higher for the constrained blocks but there was not enough statistical power in the data because this comparison is only cross-sectional (I have to calculate variance of prices for each block, then compare across blocks), whereas my main regressor (whether the quota is binding for block $b$ in month $t$ ) has both time-series and cross-sectional variation.

${ }^{37}$ An alternative specification would control for type of unit sold in the analysis of price effects (Table 4). I did do this and the results on price effects are similar. On average, prices are $4.5 \%$ higher for Chineseconstrained blocks, $2.9 \%$ lower for Malay-constrained blocks and 3.7\% lower for Indian-constrained blocks. This analysis repeats column (3) of Table 4, and also controls for dummies of the type of unit sold, and also other attributes in the transactions data (see Section 3), including the storey of the unit, and the area. Including these attributes of sold units explains $90 \%$ of the price variation. I chose to report the effects on prices and type of unit sold separately because the latter is an endogenous choice and a potential treatment effect of the policy. In other words, including controls for the types of unit sold would lead to bias from "over-controlling" (the type of unit sold could be correlated with prices, the dependent variable for Table 4, and the quota dummy, the regressor for Table 4). While I do not control for type of unit sold in Table 4, I do control for the compositional differences in the stock of HDB units using data from the census of HDB flat types. Therefore, the differences in average prices between constrained and unconstrained blocks adjust for compositional differences between these blocks.
} 
I control for whether the quota is binding in the past month and fourth order polynomials of ethnic proportions. A higher number indicates a higher priced type.

The types of unit sold in constrained blocks are lower-priced units for Chinese and Malay quotas but the magnitudes of the effects are small. Indian-constrained units that are sold are not significantly different. The marginal effects for the Chinese quotas translate to a $2.8 \%$ increase in probability for type 3 units and a $1.8 \%$ and $1.09 \%$ decrease in the probabilities for type 5 and type 6 units (all 10\% significant). The magnitudes are also small for the Malay and Indian quotas.

\section{Proportion of units sold in a block}

Table 6 reports the impact of the quota on the proportion of units sold (equation 5). As discussed in E5 in the theory, we expect $\beta$ to be negative. Panel A includes all HDB blocks that have appeared in the resale transactions website. Panel B includes all HDB blocks in the Ethnic Integration Policy website, including blocks that did not have a resale transaction during my sample period (I set proportion units sold to 0 for these blocks). My preferred specification includes town fixed effects (there are no month fixed effects because this specification collapses the transactions level data used to estimate price effects to the block level) and includes blocks with no units sold during my sample period (Panel B, columns 2, 5 and 8).

The proportions of units sold are 0.7 to 1.3 percentage points lower when we increase the percent of months the quota binds from zero to one. Alternatively, if we increased the main regressor (the percent of months the quota is binding for a block) by one standard deviation, the proportions of units sold falls by $0.24 \%$ for the Chinese quotas, $0.38 \%$ for the Malay quotas and $0.27 \%$ for the Indian quotas. The mean of the dependent variable is $4.5 \%$ if we include all blocks.

Another way is to translate these effects into durations. On average, $0.27 \%$ of units in a block are sold in a month. Going from no exposure to full exposure (increasing the regressor from zero to one) translates to units being on the market 3 months longer for the Chinese and Indian quotas and 5 months longer for the Malay quotas. If we increased the key regressor by one standard deviation, we would increase the duration on the market by about one month for the Chinese and Indian quotas and 1.4 months for the Malay quotas. These effects are economically significant. Ong and Koh (2000) report that the mean time on market is less than two months and the median is slightly longer than a month (42 days).

The incidence of this effect is likely to fall more on non-segregated sellers because sellers from the segregated group can sell to all ethnic groups. These quantity effects are larger than those in the literature. For example, Marion (2009) finds that the removal of affirmative action policies on state-funded procurement contracts did not affect the average 
number of bidders. Krasnokutskaya and Seim (2011) report that preferential treatment towards small firms in highway procurement bids lead to small changes in overall participation (approximately 1\%) but large heterogeneity on participation effects for small bidders (the favored group) versus large bidders.

\subsection{Discussion of results}

In summary, I find price effects comparable to the literature and larger quantity effects. Effects on types of units sold are small. Returning to the discussion of deadweight loss and incidence at the end of Section 4, my overall assessment is that the evidence of segregation preferences from price effects point to allovative inefficiencies (not all units are sold to buyers with the highest WTP) and the quantity effects suggest some trades that have positive surplus do not occur. My overall assessment on incidence is that non-segregated sellers for the Chinese-, Malay- and Indian-constrained blocks appear to be bearing the costs (their units appear to sell for lower prices, as predicted by E1, and their units are also harder to sell). Chinese buyers of Chinese-constrained blocks are also hurt because they have to pay higher prices, as predicted by E3 (this is primarily a transfer to Chinese sellers of Chinese-constrained blocks).

These estimated policy effects on prices and quantities of sold housing units suggest the transaction value of quota-constrained units is between $13 \%$ to $27 \%$ lower than comparable, unconstrained blocks. ${ }^{38}$ Specifically, I compute how transaction value (price times quantity sold) differs for constrained and unconstrained blocks by using treatment effect estimates on prices and quantities to calculate how differences in prices and differences in quantities affect differences in transaction values. This approach allows me to determine the relative importance of quantity versus price effects. My calculations suggest that more than $80 \%$ of the impact on transaction values is due to reductions in the number of constrained units sold. ${ }^{39}$ Interestingly, even though average prices are higher for Chinese-constrained blocks, the transaction value is lower because fewer units are sold. These results illustrate how distortionary costs can arise when restrictions are imposed to encourage diversity in the housing market. ${ }^{40}$

\footnotetext{
${ }^{38}$ I provide more details of these calculations in Table A5 and Section 4 of the data appendix. However, I caution that these calculations on differences in transaction values do not represent the full efficiency effects. First, this calculation misses the values of housing units that do not sell. Second, this calculation also misses the general equilibrium effects due to the introduction of the policy (as discussed in Section 5).

${ }^{39}$ In an analysis of tipping behavior, Card, Mas, and Rothstein (2008) also find that most of the housing market response to tipping is in the quantity domain.

${ }^{40}$ To be clear, not all "distortions" are bad. For example, if there are existing imperfections such as imperfect information that leads to statistical discrimination, "distortionary effects" due to quotas could offset existing imperfections, leading to efficiency gains.
} 
These results echo some of the findings in the literature on the distortionary effects of diversity-enhancing policies. In addition to the results discussed above by Marion (2009) and Matsa and Miller (2013), Bertrand, Hanna, and Mullainathan (2010) finds that castebased affirmative action quotas in India reduce the number of females entering engineering colleges. On the other hand, McCrary (2007) finds that court-ordered hiring quotas increased the fraction of African Americans among newly hired police officers while city crime rates appear unaffected. ${ }^{41}$

An important lesson is that diversity-enhancing policies can exacerbate existing frictions, especially in the housing market. This contrasts against a literature on second-best choices suggesting distortions from diversity policies could offset existing imperfections in the market, leading to efficiency gains. ${ }^{42}$ Here, the main friction is thin markets, which are characterized with having few transactions relative to the stock. The higher average prices for Chinese-constrained units and the large quantity effects are evidence that restricting trade in thin markets can lead to worse market outcomes for both buyers and sellers. Chinese buyers have to pay higher prices because there are no substitutes in the unconstrained blocks due to thin markets. There are fewer units sold for constrained blocks, worsening the thin market problem.

Investigating distortionary effects on housing transactions is important because the ease of selling houses has been shown to affect the mobility of households. ${ }^{43}$ Effects on transaction values are also important because housing transactions have been shown to have spillover effects on the broader economy (See Mian et al. (2013); Mian and Sufi (2011)) and housing transaction taxes are an important source of tax revenue in Singapore. ${ }^{44}$

These results have policy implications beyond Singapore. As discussed in Section 2, many countries have residential desegregation programs, and some include quota limits. My results indicate that location preferences are inelastic because of segregation preferences. Placing restrictions on where households can locate to encourage desegregation can

\footnotetext{
${ }^{41}$ This is consistent with my framework. These policies impose group preferences that encourage the allocation of resources toward the favored group. The potential for allocative inefficiencies depends on how different the groups are. It is conceivable that the skill distribution for police candidates might be more similar across ethnic groups, compared to the distribution of test scores (the main admission criteria in Bertrand, Hanna, and Mullainathan (2010)) for different castes in India or the distribution of WTP in housing markets for different ethnic groups.There is a long literature on differences in test scores between ethnic groups (Clotfelter, Ladd, and Vigdor, 2009) and differences in housing preferences (Bayer, Ferreira, and McMillan, 2007).

${ }^{42}$ See, for example, Holzer and Neumark (2000); Corns and Schotter (1999); McAfee and McMillan (1989).

${ }^{43}$ There is a large literature relating housing to household mobility. See, for example, Ferreira, Gyourko, and Tracy (2010).

${ }^{44}$ In 2012, housing transaction taxes made up $10 \%$ of tax revenue in Singapore.
} 
lead to worse transaction outcomes for restricted households.

Moreover, these results suggest it might take a long time to achieve desegregation goals. In the case of Singapore, the policy bans housing transactions that increase the ethnic proportions farther above the limits. Over time, as more housing transactions occur, in effect, the policy exerts downward pressure on ethnic proportions in constrained areas. However, this process occurs slowly due to thin markets (only 5\% of the housing stock trades in a year) and inelastic preferences. The fact that many blocks are still above the quota limits sixteen years after the policy was introduced, and that there are still meaningful differences in transaction outcomes between constrained and unconstrained blocks suggest the combination of inelastic preferences and thin markets could explain why this process is so slow. In a separate paper that uses quasi-experimental variation from the quota policy to structurally estimate preferences and simulate the first best allocation of ethnic groups to neighborhoods, Wong (2013) finds that sixteen years after the policy, only $30 \%$ of neighborhoods are within one standard deviation of the first best allocation.

\subsection{Threats to identification/Alternative stories}

The preceding subsections interpret the results as treatment effects of the policy on transaction outcomes and discussed how two mechanisms of the policy can explain the estimated effects. The idea is that constrained blocks differ from unconstrained blocks because the choice restrictions of the policy could lead to differences in transaction outcomes. My empirical strategy compares transaction outcomes of constrained versus unconstrained blocks, restricting the analysis to blocks close to the quota limits, controlling flexibly for polynomials of ethnic proportions and a set of observables that can explain much of the outcome variation in my data. Still, the main concern remains that constrained and observably comparable unconstrained blocks are different along other unobservable dimensions that are also correlated outcomes. Here, I discuss possible biases to the estimates and alternative stories that could confound my results. The bottom line is the results are most consistent with the predictions of the model: the pattern of higher average prices for Chinese-constrained blocks, lower average prices for Malay- and Indian-constrained blocks, and lower proportions of units sold is most consistent with the choice restrictions of the quota causing differences in prices and quantities for constrained versus unconstrained blocks.

\section{Geographic clustering of constrained blocks and neighborhoods}

One concern is that quota dummies are not randomly assigned leading to a bias in the estimation of $\beta$ 's, as discussed in the empirical framework. Quota dummies are endogenous because ethnic proportions (used to determine quota status) are correlated with 
unobserved ethnic-specific amenities (Chinese want to live near Chinese temples, for example).

To benchmark how the spatial pattern of constrained locations deviates from random assignment, I quantify how evenly distributed quota-constrained blocks and neighborhoods are by calculating dissimilarity indices for block quotas and neighborhood quotas. This index is commonly used to measure residential segregation. It calculates the percent of households in an ethnic group who would have to change locations to produce an even distribution. Any location with an index between 30 to $60 \%$ is moderately segregated and locations with an index above $60 \%$ is very segregated (Cutler, Glaeser, and Vigdor, 1999). Instead of counting black versus white households, I apply the same idea to count constrained versus unconstrained blocks or neighborhoods. If quota status is randomly assigned, we would expect constrained blocks and neighborhoods to be evenly distributed spatially. Since there are quota limits at the block and neighborhood level, I calculate dissimilarity indices at the block and neighborhood level by using the monthly quota data from the HDB website. I provide more details on these calculations in Section 5 of the data appendix.

The average dissimilarity index for neighborhood quotas is $56 \%$ and the average dissimilarity index for block quotas is $28 \%$ indicating that neighborhood quotas are moderately clustered (a moderate number of neighborhoods will have to switch status to achieve an even distribution) but block quotas are relatively evenly distributed. Consequently, one concern is that neighborhood quota status could be correlated with unobserved amenities. To address this, I use neighborhood fixed effects to control for time invariant amenities at the neighborhood level. Some of the results are weaker with neighborhood fixed effects but still statistically significant. The quantity effects are still significant for Chinese and Malay quotas, price effects are weaker (as discussed in Section 6.1).

\section{Measurement error in ethnic proportions}

Another concern is that I do not have administrative data of ethnic proportions that HDB uses to determine which blocks are above the quota limits. In other words, my proxy for ethnic proportions (calculated using the phonebook) may not correlate with actual ethnic proportions.

To address this concern, I test whether there is a jump in the probability that the quota binds at the block quota limit. To do this, I regress the monthly quota status from the HDB website on a dummy that is 1 if ethnic proportions are above the block quota limit (calculated using the phonebook data) while controlling for fourth order polynomials of ethnic proportions. Standard errors are clustered at the block level. Figure 3a summarizes the effect of being in a block with $87 \%$ or more Chinese on the probability that the Chinese quota binds in a month. Figures $3 b$ and $3 c$ measure the same effect for Malay and Indian 
block quotas. $^{45}$

There is a statistically significantly positive discontinuity in the probability that the quota binds, right at the policy thresholds associated with the Chinese, Malay and Indian quotas. The magnitudes of the jumps are 23\%,12\% and 10\% for the Chinese, Malay and Indian quotas (all significant at the $1 \%$ level).

The probability that the quota binds is greater than 0 below the quota limits and less than 1 above the quota limits due to two reasons. First, there is time series variation because the quota data from the HDB website (vertical axis) is monthly and the phonebook data (horizontal axis) is annual. Conditional on the ethnic proportions from the phonebook data, whether a quota is binding or not can change from month to month. Secondly, there is measurement error in the matching of names to ethnicities, as discussed in the data section. The noise introduced by the measurement error would bias against finding discontinuities unless the measurement error is correlated with the quota status, which seems unlikely. This exercise validates the matching of names to ethnicities and my proxies for ethnic proportions. If the match quality was poor, we would not observe an upward jump at the quota limit (defined using the phonebook data).

\section{Endogenous supply adjustments}

Since the HDB has perfect information of the ethnic proportions (HDB uses this data to enforce the policy), it is possible that HDB expands supply differentially in areas above and below the quota limits, ${ }^{46}$ so that a comparison of constrained and unconstrained blocks could just be a comparison of unobservably different types of units. Below, I test for compositional differences in the stock of HDB units for constrained versus unconstrained blocks and find that the differences are small and cannot fully explain my main results.

I quantify compositional differences in the housing stock using the proportion of an HDB block that is of each HDB type. As discussed in Section 6.1, there are eight types of HDB units and higher types are higher price. Specifically, I use data from the HDB census to calculate the proportion of type 3 , proportion of type 4 , proportion of type 5 , proportion of type 6 units in each block. (Table 7). ${ }^{47}$ Columns 1, 3 and 5 report results using all blocks

\footnotetext{
${ }^{45}$ Figures $3 \mathrm{~b}$ and $3 \mathrm{c}$ show a kink in the predicted probability around $50 \%$ above the Malay quota limit $(25 \%)$ and the Indian quota limit (13\%) because there are too few blocks with more than $75 \%$ Malays and more than $63 \%$ Indians, given that Malays and Indians are only $14 \%$ and $8 \%$ of the population.

${ }^{46}$ Actually, while HDB does have perfect information, it may be challenging to precisely impact supply differentially around the quota limits because new units built by HDB enters into the primary lottery market only. These units are only eligible for resale after five years. For HDB to manipulate supply, it would have to predict ethnic proportions five years later. Also, HDB mostly develops new satellite towns en masse, which will make it hard to to selectively expand supply within existing towns with segregated blocks and neighborhoods. In my analysis, I use town fixed effects to control for differential supply across towns.

${ }^{47}$ There are 8 types of units. I only used 4 types in the regression because there are too few type 1 , type 2 ,
} 
that are within $10 \%$ of the Chinese, Malay and Indian quotas respectively. Columns 2, 4 and 6 report results using only blocks that were built before the policy started in 1989 .

Chinese-constrained blocks have significantly more type 4 units, but significantly fewer type 6 units (column 1, Table 7). The proportions of type 3 and type 5 units are not significantly different. While these significant differences in observable attributes are a concern, it is comforting that the sign and magnitude of the coefficients are not monotonic in the type of the units. It does not appear that Chinese-constrained units tend to have systematically more high priced units even though the Chinese are the group with the highest median income. Differences between Malay-constrained and -unconstrained blocks are statistically and economically insignificant. Malay-constrained blocks have $2 \%$ more type 6 units (10\% sig.), but the magnitude is small and this difference existed before the policy (column 4). Indian-constrained blocks have fewer type 3 units and more type 4 and type 6 units. These differences also persisted since before the quota policy was introduced (column 6).

In summary, there is some evidence of compositional differences between constrained and unconstrained blocks but these differences persisted before 1989 (they do not appear to be due to differential supply adjustements by HDB after the policy was introduced). Also, these differences are not large and all my analysis controls for these compositional differences.

\section{Unobserved housing quality}

One concern is that Chinese-constrained blocks have higher average prices (but Malayand Indian-constrained blocks do not) because the Chinese have higher income, higher income households own better houses. So, Chinese-constrained units have unobservably higher quality. If this is the case, then, we would still find price differences even if the true policy effect on prices is zero.

It is unlikely that the premium for Chinese-constrained blocks (reported in Table 4) is driven by unobserved housing quality only. First, if the quota restrictions had no impact on prices, and Chinese-constrained units are of higher quality, then, we should not see more price dispersion for Chinese-constrained units (as shown in Figure 2a) and the proportion of units sold are also unlikely to be lower for units that are more likely to be Chinese-constrained if they are higher quality (reported in Table 6). Finally, I find statistically significant price effects even after controlling for neighborhood fixed effects (this is equivalent to controlling for locational rents at the US census block group level).

Endogenous sorting around the quota limits

type 7 and type 8 units in the resale market. The R-squared of a regression of lnprice on proportion type 3 to proportion type 6 is 0.65 and including the other types only increases the R-squared by 0.007 . 
One benefit of having ethnic proportions at the block level is that I can use well-known tests in the regression kink design literature to check for endogenous sorting around the quota limits. One concern is that ethnic-based restrictions of the policy might incentivize ethnic groups to differentially sort above and below the quota limits. This endogenous sorting behavior would bias treatment effect estimates if the difference in the ethnic composition of sellers is correlated with unobserved housing quality.

I test for bunching patterns below and do not find evidence that non-random sorting is driving my treatment effect estimates. This is plausible, as suggested by Card, Lee, and Pei (2009) and discussed in Section 5, because households do not have perfect information of the ethnic proportions (this data is not public which is why I had to match names in the phonebook to ethnicities).

Figure 4 shows estimates of the densities of the running variables (McCrary, 2008). As shown in Figures $4 \mathrm{a}$ and $4 \mathrm{c}$, the densities of block level Chinese and Indian proportions are not statistically significantly discontinuous at the quota limits. The log difference in heights are -0.048 (0.06 s.e.) and .009 (0.08 s.e.) respectively. Figure 4 b shows that there is evidence of bunching right above the Malay quota limit. The log difference in height is 0.20 (0.08 s.e.).

One reason for this pattern of bunching is that Malays have very strong preferences for living in Malay enclaves perhaps because they tend to have larger families and want to live close to families. Since the policy had reduced the number of Malay enclaves tremendously, they have a lower propensity to leave Malay-constrained units. By matching names and postal codes in the 2005 and 2006 phonebook, I can identify stayers (see discussion in Section 3). Indeed, I do find that Malays are slightly more likely to stay in quota-constrained blocks. ${ }^{48}$

However, this bunching pattern is not consistent with Malays who are manipulating their treatment status. Malays who are manipulating their treatment status would have more incentive to bunch below the quota limit. Malay owners of constrained units face a trade-off of higher prices versus lower proportion of units sold. Given the small price effects and large quantity effects in Tables 4 and 6, it seems more likely that the latter effect would dominate (they would prefer to bunch below). But, I find that they bunch above (because location preferences are inelastic).

Moreover, if Malays bunched above the quota cutoff because of the prospect of higher prices (because of the effect due to $\mathrm{E} 3$ ), this would then bias against the negative price effects that I estimate in Table 4. In summary, I conclude that bunching is unlikely to

\footnotetext{
${ }^{48}$ I looked at two outcomes: The number of stayers who are Malay divided by the number of households in a block and the number of stayers who are Malay divided by the number of stayers in a block. The estimates are $0.4 \%$ for the first outcome (relative to all households) and 3.4\% for the second outcome (relative to all stayers). Both estimates are significant at the $1 \%$ level.
} 
explain the price effects in Table 4 and appears to be inconsistent with households who are manipulating their treatment status.

\section{Endogenous sorting out of public housing markets}

Another concern is that households who have strong segregation preferences (who do not like to be restricted by the quota policy) might sort into private housing markets where there are likely to be more segregated neighborhoods. Consequently, I could have a sample selection problem because I only observe transactions in the public housing market. The previous sorting problem affects the internal validity of the treatment effect estimates (constrained and unconstrained HDB blocks are not comparable) but this problem affects the external validity (HDB households are selected).

This selection problem will lead to weaker price effects. The impact of demand-side choice restrictions and segregation preferences (E1) on prices is identified off of the difference between the marginal non-segregated buyer's lower WTP for units in the constrained block and the WTP of the marginal buyer for the unconstrained block. If households with strong segregation preferences sort out of the public housing market, this difference will be smaller.

I test for the importance of this margin of selection by controlling for the share of private housing nearby, which proxies for the ease for households to sort out of the public housing markets. This test is admittedly imperfect because I do not observe the distribution of private housing before the quota policy was introduced, but it is reassuring that the treatment effects are robust to the availability of private housing nearby. I report the results in Table A6 and discuss details in Section 6 of the data appendix.

\section{Dynamic expectations of quota status}

In addition, my theoretical framework above is also static. A dynamic model could allow households to have expectations about whether the quota binds in the future. These expectations on future treatment outcomes could lead to different reservation values for sellers of constrained versus unconstrained blocks.

This type of forward-looking behavior would bias against finding discontinuities at the cutoff. For units right below the quota cutoff, if Chinese sellers knew that once the quota binds, there could be a premium for their units, the probability of capturing this premium should already be priced into units that are $\varepsilon \%$ below the quota. In this case, prices for Chinese-owned units should gradually increase as the percent of Chinese increases towards the cutoff. Equivalently, if non-Chinese buyers recognize that once the quota binds, there is a discrete downward jump in prices, this positive probability of the quota binding should be priced into units that are $\varepsilon \%$ below the quota. Hence, prices for non-Chinese-owned units should gradually decrease as the percent of Chinese increases towards $87 \%$. 


\section{Conclusion}

Many desegregation policies take the form of quotas but it is hard to find the data to evaluate these policies credibly because they are either not available publicly or there are not enough observations close to the quota limits. This paper uses a hand-collected dataset to study the impact of the ethnic housing quotas in Singapore, one of many residential desegregation programs around the world.

I develop a model that shows that distortionary effects can arise when segregated and non-segregated groups are different and some buyers' and sellers' choices are restricted. The model illustrates two main mechanisms of the policy: (i) demand-side choice restrictions and segregation preferences and (ii) supply-side choice restrictions and thin markets. I find evidence that segregation preferences are important for all three quotas. This suggests location preferences are inelastic because of segregation preferences. I also find support for supply-side constraints and thin markets for the Chinese quotas.

My results show price effects that are comparable to the literature and larger quantity effects, leading to lower transaction values for constrained blocks versus observably comparable unconstrained blocks. These results quantify the distortionary impact of a residential desegregation program using housing transactions. They also suggest that, in addition to the distortionary effects of the restrictions on housing transaction outcomes, it will take a long time to achieve desegregation through quantity restrictions because location preferences are inelastic and housing markets are thin. ${ }^{49}$ These lessons are central to the design of desegregation policies beyond Singapore's housing market.

These distortionary effects need to be weighed against the benefits from desegregation. ${ }^{50}$ This is constantly alluded to in the parliamentary debates in Singapore when the costs and benefits of the policy are discussed (see Section 2). Quotas could lead to welfare improvements by preventing extremely segregated outcomes. Due to externalities and tipping behavior, a decentralized equilibrium may have too many segregated neighborhoods relative to the first best. ${ }^{51}$ By preventing neighborhoods from becoming extremely segre-

\footnotetext{
${ }^{49}$ The relationship between choice heterogeneity and the distortionary effects due to choice restrictions echoes the literature on the relative inefficiencies of quantity restrictions in international trade (this literature emphasizes inefficiencies when products are differentiated and consumers have to imperfectly substitute from consuming restricted products to consuming unrestricted products due to trade quotas). In housing, imperfections due to thin markets can be large and further exacerbated by choice restrictions due to quotas because of the two types of choice heterogeneity (segregation preferences and thin markets) highlighted in my model.

${ }^{50}$ For example, Beaman et al. (2012) quantify the benefit of introducing gender quotas in politics and Edin, Fredriksson, and Åslund (2004) study the benefits of a residential desegregation policy on immigrants.

${ }^{51}$ In a decentralized equilibrium, the first best allocation of ethnic groups may not be achieved because of externalities (An individual chooses the neighborhood that maximizes his own utility, without internalizing the effect of his choice on the ethnic proportions in the neighborhood).
} 
gated, if households prefer diversity, then, quotas could lead to welfare improvements.

In future work, it would be useful to have transaction level data by buyer and seller ethnicity to study incidence. Another important outcome to look at would be the time the property stays on the market. It would be useful to get pre-policy data, to test for general equilibrium effects of the policy. Finally, it should be noted that the analysis in this paper focuses on transactions close to the quota limits and results may differ for transactions further away from the quota limits. 


\section{References}

Altonji, J., Elder, T., Taber, C., 2005. Selection on Observed and Unobserved Variables: Assessing the Effectiveness of Catholic Schools. Journal of Political Economy 113 (1), 151-184.

Angrist, J., Lavy, V., 1999. Using Maimonides' Rule to Estimate the Effect of Class Size on Scholastic Achievement. Quarterly Journal of Economics 114 (2), 533-575.

Arnott, R., February 1989. Housing vacancies, thin markets, and idiosyncratic tastes. The Journal of Real Estate Finance and Economics 2 (1), 5-30.

Autor, D., Palmer, C., Pathak, P., 2012. Housing Market Spillovers: Evidence from the End of Rent Control in Cambridge Massachusetts, nBER Working Paper No. 18125.

Banhardt, S., 2009. Near and Dear? Evaluating the Impact of Neighbor Diversity on InterReligious Attitues. Ph.D. thesis, Harvard University.

Bayer, P., Ferreira, F., McMillan, R., 2007. A Unified Framework for Measuring Preferences for Schools and Neighborhoods. Journal of Political Economy 115 (4), 588-638.

Bayer, P., McMillan, R., Rueben, K., 2004. What Drives Racial Segregation? New Evidence Using Census Microdata. Journal of Urban Economics 56 (3), 514-535.

Beaman, L., Duflo, E., Pande, R., Topalova, P., 2012. Female Leadership Raises Aspirations and Educational Attainment for Girls: A Policy Experiment in India. Science 335 (6068), 582-586.

Bellows, J., Miguel, E., 2009. Was and Local Collective Action in Sierra Leone. Journal of Public Economics 93 (11), 1144-1157.

Benabou, R., 1993. Workings of a City: Location, Education, and Production. The Quarterly Journal of Economics 108 (3), 619-652.

Berry, S. T., 1994. Estimating Discrete-Choice Models of Product Differentiation. The Rand Journal of Economics 25 (2), 242-262.

Berry, S. T., Levinsohn, J., Pakes, A., 1995. Automobile Prices in Market Equilibrium. Econometrica 63 (4), 841-890.

Bertrand, M., Hanna, R., Mullainathan, S., 2010. Affirmative Action: Evidence from College Admissions in India. Journal of Public Economics 94 (1), 16-29. 
Boisjoly, J., Duncan, G., Kremer, M., Levy, D., Eccles, J., 2006. Empathy or Antipathy? The Impact of Diversity. American Economic Review 96 (5), 1890-1905.

Boustan, L., 2011. Racial Residential Segregation in American Cities. In: Brooks, N., Knaap, G.-J. (Eds.), Oxford Handbook of Urban Economics and Planning. Oxford University Press, pp. 318-339.

Card, D., Lee, D., Pei, Z., 2009. Quasi-Experimental Identification and Estimation in the Regression Kink Design, princeton University Industrial Relations Section Working Paper 553.

Card, D., Mas, A., Rothstein, J., 2008. Tipping and the Dynamics of Segregation. Quarterly Journal of Economics 123 (1), 177-218.

Chay, K., Fairlie, R., 1998. Minority Business Set-Asides and Black Self-Employment. University of California, Berkeley: Mimeo.

Chetty, R., Friedman, J., Olson, T., Pistaferri, L., 2011. Adjustment Costs, Firm Responses, and Micro vs Macro Labor Supply Elasticities: Evidence from Danish Tax Records. Quarterly Journal of Economics 126 (2), 749-804.

Clotfelter, C., Ladd, H., Vigdor, J., 2009. The Academic Achievement Gap in Grades 3 to 8. Journal of Economics and Statistics 91 (2), 398-419.

Corns, A., Schotter, A., 1999. Can Affirmative Action Be Cost Effective? An Experimental Examination of Price-Preference Auctions. American Economic Review 89 (1), 291-305.

Cutler, D. M., Glaeser, E. L., Vigdor, J. L., 1999. The Rise and Decline of the American Ghetto. Journal of Political Economy 107 (3), 455-506.

Dutch Refugee Council, 1999. Housing for refugees in the european union. Tech. rep., Dutch Refugee Council.

Edin, P.-A., Fredriksson, P., Åslund, O., 2003. Ethnic Enclaves and the Economic Success of Immigrants-Evidence from a Natural Experiment. Quarterly Journal of Economics 118 (1), 329-357.

Edin, P.-A., Fredriksson, P., Åslund, O., 2004. Settlement Policies and the Economic Success of Immigrants. Journal of Population Economics 17 (1), 133-155.

Epple, D., Romer, T., Sieg, H., 2001. Interjurisdictional Sorting and Majority Rule: An Empirical Analysis. Econometrica 69 (6), 1437-1466. 
Epple, D., Sieg, H., 1997. Estimating Equilibrium Models of Local Jurisdictions. Journal of Political Economy 107 (4), 645-681.

Ferreira, F., Gyourko, J., Tracy, J., 2010. Housing Busts and Household Mobility. Journal of Urban Economics 68 (1), 34-45.

Gabriel, S., Rosenthal, S., 1989. Household Location and Race: Estimates of a Multinomial Logit Model. The Review of Economics and Statistics 71 (2), 240-249.

Gavazza, A., June 2011. The role of trading frictions in real asset markets. American Economic Review 101 (4), 1106-43.

Glitz, A., 2012. The Labor Market Impact of Immigration: A Quasi-Experiment Exploiting Immigrant Location Rules in Germany. Journal of Labor Economics 30 (1), 175213.

Hahn, J., Todd, P., van der Klaauw, W., 2001. Identification and Estimation of Treatment Effects with a Regression-Discontinuity Design. Econometrica 69 (1), 201-209.

Hendel, I., Nevo, A., Ortalo-Magne, F., 2009. The relative performance of real estate marketing platforms: Mls versus fsbomadison.com. American Economic Review 99 (5), 1878-98.

Holzer, H., Neumark, D., 2000. Assessing Affirmative Action. Journal of Economic Literature $38(3), 483-568$.

Housing Development Board, 2006. Annual Report. Singapore: HDB.

Imbens, G., Lemieux, T., 2008. Regression Discontinuity Designs: A Guide to Practice. Journal of Economics 142 (2), 615-635.

Inland Revenue Authority of Singapore, 2013. IRAS Collection by Tax Type. https://www .iras.gov.sg/irasHome/page. aspx?id=15060\#SD, accessed: 20139-30.

Krasnokutskaya, E., Seim, K., 2011. Bid Preference Programs and Participation in Highway Procurement Autctions. American Economic Review 101 (6), 2653-2686.

Krook, M., 2009. Quotas for Women in Politics: Gender and Candidate Selection Reform Worldwide. Oxford University Press: New York.

Lai, A. E., 1995. Meanings of Multiethnicity: A Case Study of Ethnicity and Ethnic Relations in Singapore. Oxford University Press. 
Lee, D. S., Lemieux, T., 2010. Regression discontinuity designs in economics. Journal of Economic Literature 48 (2), 281-355.

Levitt, S. D., Syverson, C., 2008. Market distortions when agents are better informed: The value of information in real estate transactions. The Review of Economics and Statistics $90(4), 599-611$.

Lum, S. K., Tien, T. M., 2003. Integrating Differentials: A Study on the HDB Ethnic Integration Policy. Crestimes, Singapore Center for Real Estate (CRES) 3 (1), 5.

Marion, J., 2009. How Costly is Affirmative Action? Government Contracting and California's Proposition 209. The Review of Economics and Statistics 91 (3), 503-522.

Marion, J., 2011. Affirmative Action and the Utilization of Minority- and Women-Owned Businesses in Highway Procurement. Economic Inquiry 49 (3), 899-915.

Matsa, D., Miller, A., 2013. A Female Style in Corporate Leadership? Evidence from Quotas. American Economic Journal: Applied Economics 5 (3), 136-169.

McAfee, P., McMillan, J., 1989. Government Procurement and International Trade. Journal of International Economics 26 (3), 291-308.

McCrary, J., 2007. The Effect of Court-Ordered Hiring Quotas on the Composition and Quality of Police. American Economic Review 97 (1), 318-353.

McCrary, J., 2008. Manipulation of the Running Variable in the Regression Discontinuity Design: A Desity Test. Journal of Econometrics 142 (12), 698-714.

McFadden, D., 1973. Conditional Logit Analysis of Qualitative Choice Behavior. In: Zarembka, P. (Ed.), Frontiers in Econometrics. Academy Press, New York.

McFadden, D., 1978. Modelling the Choice of Residential Location. In: Karlqvist, A. (Ed.), Spatial Interaction Theory and Planning Models. North-Holland, New York.

Mian, A., Rao, K., Sufi, A., 2013. Household Balance Sheets, Consumption, and the Economic Slump. Chicago Booth Research Paper No. 13-42.

Mian, A., Sufi, A., 2011. House Prices, Home Equity-Based Borrowing, and the US Household Leverage Crisis. American Economic Review 101 (5), 2132-2156.

Nechyba, T. J., Strauss, R. P., 1998. Community Choice and Local Public Services: A Discrete Choice Approach. Regional Science and Urban Economics 28 (1), 51-73. 
Nunn, N., Wantchekon, L., 2011. The Slave Trade and the Origins of Mistrust in Africa. American Economic Review 101 (7), 3221-3252.

Ong, S. E., Koh, Y. C., 2000. Time On-Market and Price Trade-Offs in High-Rise Housing Sub-Markets. Urban Studies 37, 2057-2071.

Parliamentary Debates, 1989. Official Report, 16 February, singapore.

Parliamentary Debates, 2003. Official Report, 10 November, singapore.

Polikoff, A., 1986. Sustainable Intergration or Inevitable Resegregation. University of North Carolina Press, pp. 41-71.

Quigley, J. M., 1985. Consumer Choice of Dwelling, Neighborhood, and Public Services. Regional Science and Urban Economics 15 (1), 41-63.

Rosenbaum, J., 1995. Changing the Geography of Opportunity by Expanding Residential choice: Lessons from the Gautreaux Program. Housing Policy Debate 6 (1), 231-269.

Saez, E., 2010. Do Tax Payers Bunch at Kink Points? American Economic Journal: Economic Policy 2 (3).

Scott, J., 2006. A sweeping housing plan bedeviled by racial quotas. New York Times December 1, 2006.

Singapore Department of Statistics, 2000. Singapore 2000 census: Key Indicators of the Resident Population.

Singapore Department of Statistics, 2006. Singapore Resident Population, 1990 - 2006.

Sowell, T., 2004. Affirmative Action Around the World. Yale University Press: New Haven \& London.

Tiebout, C. M., 1956. A Pure Theory of Local Expenditures. Journal of Political Economy 64 (5), 416-424.

Tu, Y., Wong, G. K., 2002. Public Policies and Public Resale Housing Prices in Singapore. International Real Estate Review 5, 115-132.

Wang, S., 2011. State Misallocation and Housing Prices: Theory and Evidence from China. American Economic Review 101 (5), 2081-2107.

Wong, M., 2013. Estimating Ethnic Preferences Using Ethnic Housing Quotas in Singapre. Review of Economic Studies 80 (3), 1178-1214. 
Table 1

Neighborhood and block level ethnic quotas ${ }^{\text {a }}$

\begin{tabular}{lccc}
\hline & Neighborhood Quotas & Block Quotas & National Proportion (2000) \\
\hline Chinese & $84 \%$ & $87 \%$ & $77 \%$ \\
Malay & $22 \%$ & $25 \%$ & $14 \%$ \\
Indian & $10 \%$ & $13 \%$ & $8 \%$ \\
\hline
\end{tabular}

${ }^{\text {a }}$ Source: 2000 Census (Singstat), Lum and Tan (2003)

Table 2

Summary statistics

\begin{tabular}{|c|c|c|c|c|c|c|c|}
\hline Variable & $\mathrm{N}$ & Mean & Std. Dev. & Min & Max & Level & Description \\
\hline Price & 35744 & 234016 & 71943 & 40000 & 635000 & Transaction & Transaction price (Singapore dollars, $1 \mathrm{USD}=1.62 \mathrm{SGD}$ as of Mar 2005) \\
\hline Flat type sold & 35744 & 4 & 1 & 1 & 8 & Transaction & Flat type sold \\
\hline Age & 35744 & 18.20 & 9.24 & 3.00 & 40.00 & Transaction & Age of flat sold \\
\hline Chinese Quota & 133378 & 0.11 & 0.31 & 0 & 1 & Month-Block & Whether Chinese quota binds \\
\hline Malay Quota & 133378 & 0.12 & 0.32 & 0 & 1 & Month-Block & Whether Malay quota binds \\
\hline Indian Quota & 133378 & 0.22 & 0.41 & 0 & 1 & Month-Block & Whether Indian quota binds \\
\hline Percent Sold & 7222 & $4.99 \%$ & $3.02 \%$ & $0.34 \%$ & $50.00 \%$ & Block & Percent of units in a block that was sold within the sample period \\
\hline Percent Chinese & 8007 & $77.91 \%$ & $10.64 \%$ & $0.00 \%$ & $100.00 \%$ & Block & Percent of Chinese in a block \\
\hline Percent Malay & 8007 & $13.81 \%$ & $9.40 \%$ & $0.00 \%$ & $100.00 \%$ & Block & Percent of Malay in a block \\
\hline Percent Indian & 8007 & $8.28 \%$ & $5.55 \%$ & $0.00 \%$ & $83.33 \%$ & Block & Percent of Indian in a block \\
\hline Percent Type 1 & 8007 & $0.05 \%$ & $1.78 \%$ & $0.00 \%$ & $99.24 \%$ & Block & Percent of units in a block that is Type 1 \\
\hline Percent Type 2 & 8007 & $0.97 \%$ & $8.26 \%$ & $0.00 \%$ & $100.00 \%$ & Block & Percent of units in a block that is Type 2 \\
\hline Percent Type 3 & 8007 & $23.42 \%$ & $36.78 \%$ & $0.00 \%$ & $100.00 \%$ & Block & Percent of units in a block that is Type 3 \\
\hline Percent Type 4 & 8007 & $37.63 \%$ & $34.07 \%$ & $0.00 \%$ & $100.00 \%$ & Block & Percent of units in a block that is Type 4 \\
\hline Percent Type 5 & 8007 & $24.88 \%$ & $32.07 \%$ & $0.00 \%$ & $100.00 \%$ & Block & Percent of units in a block that is Type 5 \\
\hline Percent Type 6 & 8007 & $12.97 \%$ & $32.24 \%$ & $0.00 \%$ & $100.00 \%$ & Block & Percent of units in a block that is Type 6 \\
\hline Percent Type 7 & 8007 & $0.01 \%$ & $1.12 \%$ & $0.00 \%$ & $100.00 \%$ & Block & Percent of units in a block that is Type 7 \\
\hline Percent Type 8 & 8007 & $0.08 \%$ & $2.62 \%$ & $0.00 \%$ & $100.00 \%$ & Block & Percent of units in a block that is Type 8 \\
\hline
\end{tabular}




\section{Thought experiment:}

Compare transactions for blocks with $86 \%$ Chinese (unconstrained) versus $88 \%$ Chinese (constrained)

\section{Types of transactions:}

Type 1: non-Chinese seller to Chinese buyer (banned)

Type 2: non-Chinese seller to non-Chinese buyer

Type 3: Chinese seller to non-Chinese buyer

Type 4: Chinese seller to Chinese buyer

* Notation: Let $P_{b}^{t}$ denote prices for transaction type $t$ in block $b$.

\section{Predictions:}

E1: Prices for type 2 trades will be lower in the constrained blocks, $P_{88}^{2} \leq P_{86}$

Non-Chinese sellers in the $88 \%$ blocks cannot sell to Chinese buyers. So, they have to accept lower transaction prices, in order to attract non-Chinese buyers. This is an example of demand-side choice restrictions leading to lower prices because of segregation preferences.

E2: Non-Chinese buyers pay the same price regardless of seller ethnicity for constrained blocks, $P_{88}^{2}=P_{88}^{3}$

There are no restrictions that limit non-Chinese buyers from arbitraging price differences between Chinese and non-Chinese sellers, so the prices of type 2 and type 3 trades should not differ in equilibrium for the $88 \%$ block.

E3: Chinese buyers pay weakly higher prices for constrained blocks, $P_{88}^{4} \geq P_{86}$

Chinese buyers cannot buy from non-Chinese sellers of the $88 \%$ blocks. If markets are thin, there could be a wedge in the willingnessto-pay between the marginal Chinese buyer's most preferred unit (that happens to be in the $88 \%$ block) and the second most preferred unit (that happens to be in the $86 \%$ block). This is an example of supply-side choice restrictions leading to higher prices because of thin markets.

E4: $\overline{P_{88}} \geq P_{86}$. The inequality is the reverse for Malay and Indian quotas.

Given E2, we can rewrite the differences in average prices as $\left(s^{2}+s^{3}\right)\left(P_{88}^{2}-P_{86}\right)+s^{4}\left(P_{88}^{4}-P_{86}\right) \geq 0$. The first difference is weakly negative (E1). The second difference is weakly positive (E3). We can bound the shares of transaction types for the constrained blocks. In the $88 \%$ blocks, there are $12 \%$ of non-Chinese $\left(s^{2} \leq 12 \%\right)$. Because of E2 and E3, most Chinese sellers will sell to Chinese buyers first $\left.s^{3} \leq s^{4}\right)$. Therefore, the overall effect on prices is likely to be heavily weighted towards the weakly positive price difference $\left(s^{4}\right.$ is high). Finally, I use the phonebook data to check that the share of movers moving into Chinese-constrained blocks who are Chinese is $74 \%$ (approximation of $s^{4}$ ) while the share who are non-Chinese is only $26 \%$ (approximation of $\left(s^{2}+s^{3}\right)$. The inequality is the reverse for Malay and Indian quotas because the Chinese (the majority in Singapore) are part of the non-Malay and non-Indian groups.

E5: Number of type 2 and type 3 trades is weakly lower, the number of type 4 trades is weakly higher

Given the same distribution of reservation values of sellers, as transaction prices fall, the number of transactions would be weakly lower. Given E1 and E2, the number of type 2 and type 3 trades is weakly lower. Conversely, given E3, the number of type 4 trades is weakly higher. 
Table 4

Results of the quota impact on price ${ }^{\mathrm{a}}$

\begin{tabular}{|c|c|c|c|c|c|}
\hline Dependent variable & $\begin{array}{c}\text { In price } \\
\text { (1) }\end{array}$ & $\begin{array}{l}\text { In price } \\
(2) \\
\end{array}$ & $\begin{array}{c}\ln \text { price } \\
(3) \\
\end{array}$ & $\begin{array}{c}\ln \text { price } \\
(4)\end{array}$ & $\begin{array}{c}\text { In price } \\
(5) \\
\end{array}$ \\
\hline \multicolumn{6}{|l|}{ Panel A: Chinese quota } \\
\hline \multirow[t]{2}{*}{$\overline{\mathrm{C}}$} & $.081^{* * *}$ & $.0503 * * *$ & $.0502 * * *$ & $.0321 * * *$ & -0.00413 \\
\hline & $(.0166)$ & $(.0102)$ & $(.0104)$ & $(.00664)$ & $(.00872)$ \\
\hline$\overline{\mathrm{N}}$ & 19533 & 19533 & 19533 & 19533 & 19533 \\
\hline R-squared & 0.00926 & 0.798 & 0.799 & 0.825 & 0.892 \\
\hline \multicolumn{6}{|l|}{ Panel B: Malay quota } \\
\hline \multirow[t]{2}{*}{$\mathrm{M}$} & $-.0396 * * *$ & $-.0262 * * *$ & $-.027 * * *$ & $-.00697 *$ & 0.00564 \\
\hline & $(.0116)$ & $(.00762)$ & $(.00803)$ & $(.00374)$ & $(.00635)$ \\
\hline $\mathrm{N}$ & 14921 & 14921 & 14921 & 14921 & 14921 \\
\hline$\underline{R \text {-squared }}$ & 0.0039 & 0.747 & 0.748 & 0.776 & 0.846 \\
\hline \multicolumn{6}{|l|}{ Panel C: Indian quota } \\
\hline \multirow[t]{2}{*}{$\bar{I}$} & $-.0285^{* * *}$ & $-.0332 * * *$ & $-.0341^{* * *}$ & $-.0109 * *$ & 0.00133 \\
\hline & $(.0108)$ & $(.0109)$ & $(.0114)$ & $(.00488)$ & $(.00478)$ \\
\hline $\mathrm{N}$ & 32147 & 32147 & 32147 & 32147 & 32147 \\
\hline R-squared & 0.00908 & 0.775 & 0.776 & 0.806 & 0.875 \\
\hline Ethnic proportions & $\mathrm{Y}$ & $\mathrm{Y}$ & $\mathrm{Y}$ & $\mathrm{Y}$ & $\mathrm{N}$ \\
\hline Controls & $\mathrm{N}$ & $\mathrm{Y}$ & $\mathrm{Y}$ & $\mathrm{Y}$ & $\mathrm{N}$ \\
\hline Month & $\mathrm{N}$ & $\mathrm{Y}$ & $\mathrm{Y}$ & $\mathrm{Y}$ & $\mathrm{N}$ \\
\hline Town & $\mathrm{N}$ & $\mathrm{Y}$ & $\mathrm{Y}$ & $\mathrm{N}$ & $\mathrm{N}$ \\
\hline Linear town-by-month trend & $\mathrm{N}$ & $\mathrm{N}$ & $\mathrm{Y}$ & $\mathrm{N}$ & $\mathrm{N}$ \\
\hline Neighborhood & $\mathrm{N}$ & $\mathrm{N}$ & $\mathrm{N}$ & Y & $\mathrm{N}$ \\
\hline Block & $\mathrm{N}$ & $\mathrm{N}$ & $\mathrm{N}$ & $\mathrm{N}$ & $\mathrm{Y}$ \\
\hline
\end{tabular}

${ }^{\mathrm{a}}$ The regression equation is InPrice $_{\mathrm{ibkt}}=\alpha+\beta Q C_{\mathrm{bk},-1-1}+\Sigma_{l=1}^{4} \varphi_{l}\left(\text { percent }_{b k}-0.87\right)^{l}+\varepsilon_{i b k t}$ where InPrice $_{\mathrm{ibkt}}$ is the $\log$ of the price of transaction $i$ in block $b$, town $k$ and month $t ; Q C_{b k, t-1}$ is a dummy that is 1 if the Chinese quota is binding in the previous month; (percent $\left.C_{b k}-0.87\right)^{l}$ are $t^{\mathrm{t}}$ order polynomials of percent Chinese, centered around the block quota. The controls are other observable characteristics of the block (age of block, its squared, proportion of type 2 units, proportion of type 3 units, proportion of type 4 units, proportion of type 5 units, proportion of type 6 units, proportion of type 7 units, proportion of type 8 units). I repeat the exercise for the Malay quota (Panel B) and for the Indian quota (Panel C). All specifications only use blocks that are within $10 \%$ of the Chinese, Malay, and Indian quota cutoffs, respectively. Standard errors are in parentheses, clustered at the block level (columns 1 and 5), town level (columns 2 and 3), neighborhood level (column 4 ). ${ }^{* * *}$ Statistically significant at $1 \%$. ${ }^{*}$ Statistically significant at $5 \%$. Statistically significant at $10 \%$. 
Table 5

Results of the quota impact on type of unit sold ${ }^{\mathrm{a}}$

\begin{tabular}{|c|c|c|c|}
\hline $\begin{array}{l}\text { Quota } \\
\text { Dependent variable }\end{array}$ & $\begin{array}{c}\text { Chinese } \\
\text { Flat Type Sold } \\
(1)\end{array}$ & $\begin{array}{c}\text { Malay } \\
\text { Flat Type Sold } \\
(2) \\
\end{array}$ & $\begin{array}{c}\text { Indian } \\
\text { Flat Type Sold } \\
(3) \\
\end{array}$ \\
\hline Quota dummy & $\begin{array}{l}-.0841 * \\
(.0496)\end{array}$ & $\begin{array}{l}-.0854 * \\
(.0449)\end{array}$ & $\begin{array}{l}0.0273 \\
(.0364)\end{array}$ \\
\hline Ethnic proportion & $\begin{array}{l}-1.56 \\
(1.06)\end{array}$ & $\begin{array}{l}1.99 * \\
(1.17)\end{array}$ & $\begin{array}{c}-2.79 * * * \\
(1.04)\end{array}$ \\
\hline (Ethnic proportion) $^{2}$ & $\begin{array}{l}28.2 \\
(25)\end{array}$ & $\begin{array}{c}24.1 \\
(26.8)\end{array}$ & $\begin{array}{c}-39.7 * * \\
(20.1)\end{array}$ \\
\hline$(\text { Ethnic proportion) })^{3}$ & $\begin{array}{c}76.1 \\
(200)\end{array}$ & $\begin{array}{l}-140 \\
(179)\end{array}$ & $\begin{array}{c}291 \\
(191)\end{array}$ \\
\hline$(\text { Ethnic proportion })^{4}$ & $\begin{array}{l}-3134 \\
(3223)\end{array}$ & $\begin{array}{l}-1830 \\
(3149)\end{array}$ & $\begin{array}{l}6276^{* *} \\
(2639)\end{array}$ \\
\hline Type 1 & $\begin{array}{c}-2.92 * * * \\
(.312)\end{array}$ & $\begin{array}{l}-2.2 * * * \\
(.0675)\end{array}$ & $\begin{array}{c}-3.06 * * * \\
(.29)\end{array}$ \\
\hline Type 2 & $\begin{array}{c}-2.25 * * * \\
(.0801)\end{array}$ & $\begin{array}{l}-.517 * * * \\
(.0461)\end{array}$ & $\begin{array}{l}-2.16 * * * \\
(.0515)\end{array}$ \\
\hline Type 3 & $\begin{array}{c}-.406 * * * \\
(.0379)\end{array}$ & $\begin{array}{l}.596 * * * \\
(.0423)\end{array}$ & $\begin{array}{l}-.357 * * * \\
(.0339)\end{array}$ \\
\hline Type 4 & $\begin{array}{l}.551 * * * \\
(.034)\end{array}$ & $\begin{array}{l}1.54 * * * \\
(.0479)\end{array}$ & $\begin{array}{l}.623 * * * \\
(.0329)\end{array}$ \\
\hline Type 5 & $\begin{array}{l}1.51 * * * \\
(.0391)\end{array}$ & dropped & $\begin{array}{l}1.51 * * * \\
(.0372)\end{array}$ \\
\hline Type 6 & $\begin{array}{c}3.52 * * * \\
(.165)\end{array}$ & dropped & $\begin{array}{l}3.39 * * * \\
(.128)\end{array}$ \\
\hline Type 7 & $\begin{array}{c}3.65 * * * \\
(.196)\end{array}$ & dropped & $\begin{array}{c}3.44 * * * \\
(.14)\end{array}$ \\
\hline Observations & 19533 & 14868 & 32147 \\
\hline
\end{tabular}

${ }^{a}$ This is an ordered probit regression where the dependent variable is an integer between one and eight. The regressors are the same as column 1 of Table 5 . All specifications only use blocks that are within $10 \%$ of the Chinese, Malay, and Indian quota cutoffs, respectively. Standard errors are in parentheses, clustered at the block level. ${ }^{* *}$ Statistically significant at $1 \%$. $* *$ Statistically significant at $5 \%$. ${ }^{*}$ Statistically significant at $10 \%$. 
Table 6

Results of the quota impact on the proportion of units sold ${ }^{\mathrm{a}}$

\begin{tabular}{|c|c|c|c|c|c|c|c|c|c|}
\hline \multirow{2}{*}{$\begin{array}{l}\text { Quota } \\
\text { Dependent variable }\end{array}$} & \multicolumn{3}{|c|}{ Chinese } & \multicolumn{3}{|c|}{ Malay } & \multicolumn{3}{|c|}{ Indian } \\
\hline & $\begin{array}{c}\text { Proportion Sold } \\
\text { (1) }\end{array}$ & $\begin{array}{c}\text { Proportion Sold } \\
\text { (2) }\end{array}$ & $\begin{array}{c}\text { Proportion Sold } \\
\text { (3) }\end{array}$ & $\begin{array}{c}\text { Proportion Sold } \\
\text { (4) }\end{array}$ & $\begin{array}{c}\text { Proportion Sold } \\
\text { (5) }\end{array}$ & $\begin{array}{c}\text { Proportion Sold } \\
\text { (6) }\end{array}$ & $\begin{array}{c}\text { Proportion Sold } \\
\text { (7) }\end{array}$ & $\begin{array}{c}\text { Proportion Sold } \\
(8)\end{array}$ & $\begin{array}{c}\text { Proportion Sold } \\
(9)\end{array}$ \\
\hline \multicolumn{10}{|c|}{ Panel A: Only blocks with resale transactions } \\
\hline Probability quota binds & $\begin{array}{c}-.00544^{* * * *} \\
(.00125)\end{array}$ & $\begin{array}{c}-.00456^{* *} \\
(.00177)\end{array}$ & $\begin{array}{c}-.00625^{* * * *} \\
(.00178)\end{array}$ & $\begin{array}{l}-.0102 * * * \\
(.00147)\end{array}$ & $\begin{array}{c}-.00647^{* * * *} \\
(.00136)\end{array}$ & $\begin{array}{l}-.00348^{*} \\
(.00207)\end{array}$ & $\begin{array}{c}-.00623 * * * \\
(.000952)\end{array}$ & $\begin{array}{l}-.00466^{* *} \\
(.00193)\end{array}$ & $\begin{array}{l}-0.00171 \\
(.00172)\end{array}$ \\
\hline $\mathrm{N}$ & 3980 & 3980 & 3980 & 2906 & 2906 & 2906 & 6324 & 6324 & 6324 \\
\hline$\underline{\text { R-squared }}$ & 0.0134 & 0.095 & 0.148 & 0.0172 & 0.121 & 0.188 & 0.0209 & 0.11 & 0.147 \\
\hline \multicolumn{10}{|c|}{ Panel B: Includes blocks without resale transactions } \\
\hline Probability quota binds & $\begin{array}{r}-0.00195 \\
(.00127) \\
\end{array}$ & $\begin{array}{c}-.00791^{* * * *} \\
(.00147)\end{array}$ & $\begin{array}{c}-.00935^{\text {**** }} \\
(.0019)\end{array}$ & $\begin{array}{c}-.00909^{* * * *} \\
(.0016)\end{array}$ & $\begin{array}{c}-.0131^{* * * *} \\
(.00237)\end{array}$ & $\begin{array}{c}-.00783^{* * * *} \\
(.00236)\end{array}$ & $\begin{array}{c}-.00363^{* * * *} \\
(.00102)\end{array}$ & $\begin{array}{c}-.00729 * * \\
(.00307)\end{array}$ & $\begin{array}{r}-0.00135 \\
(.00181) \\
\end{array}$ \\
\hline $\mathrm{N}$ & 4347 & 3980 & 3980 & 3149 & 2906 & 2906 & 6818 & 6324 & 6324 \\
\hline$\underline{\mathrm{R} \text {-squared }}$ & 0.0109 & 0.0745 & 0.142 & 0.0103 & 0.097 & 0.181 & 0.00482 & 0.0863 & 0.137 \\
\hline Ethnic proportions & $\mathrm{Y}$ & $\mathrm{Y}$ & $\mathrm{Y}$ & $\mathrm{Y}$ & $\mathrm{Y}$ & $\mathrm{Y}$ & $\mathrm{Y}$ & $\mathrm{Y}$ & $\mathrm{Y}$ \\
\hline Controls & $\mathrm{N}$ & $\mathrm{Y}$ & $\mathrm{Y}$ & $\mathrm{N}$ & $\mathrm{Y}$ & $\mathrm{Y}$ & $\mathrm{N}$ & $\mathrm{Y}$ & $\mathrm{Y}$ \\
\hline Town & $\mathrm{N}$ & $\mathrm{Y}$ & $\mathrm{N}$ & $\mathrm{N}$ & $\mathrm{Y}$ & $\mathrm{N}$ & $\mathrm{N}$ & $\mathrm{Y}$ & $\mathrm{N}$ \\
\hline Neighborhood & $\mathrm{N}$ & $\mathrm{N}$ & $\mathrm{Y}$ & $\mathrm{N}$ & $\mathrm{N}$ & $\mathrm{Y}$ & $\mathrm{N}$ & $\mathrm{N}$ & $\mathrm{Y}$ \\
\hline
\end{tabular}

${ }^{a}$ The regression equation is $p S o l d_{b k}=\alpha+\beta$ percent $Q C_{b k}+\Sigma_{l=1}^{4} \varphi_{l}$ percent $C_{b k}^{l}+\varepsilon_{b k}$ where $p S o l d_{b k}$ is the proportion of units sold in block $b$, town $k$, aggregated across months; percent $Q C_{b k}$ is the proportion of months the Chinese (C) quota is binding; percent $C_{b k}$ are $l^{\text {th }}$ order polynomials of percent Chinese. All specifications only use observations within $10 \%$ of the quota cutoffs. I repeat the exercise for the Malay and for the Indian quotas. Standard errors in parentheses, clustered at the block level (columns 1, 4 and 7), town level (columns 2, 5 and 8) and neighborhood level (columns 3,6 and 9). ${ }^{* * * S t a t i s t i c a l l y ~}$ significant at $1 \%$. ** Statistically significant at $5 \%$. * Statistically significant at $10 \%$. 
Table 7

Testing differences in proportion of unit types ${ }^{\mathrm{a}}$

\begin{tabular}{|c|c|c|c|c|c|c|}
\hline \multirow{2}{*}{$\begin{array}{l}\text { Quota } \\
\text { Sample } \\
\text { Dependent variable } \\
\end{array}$} & \multicolumn{2}{|c|}{ Chinese } & \multicolumn{2}{|c|}{ Malay } & \multicolumn{2}{|c|}{ Indian } \\
\hline & $\begin{array}{l}\text { Pre- and Post- Quota } \\
\text { (1) }\end{array}$ & $\begin{array}{l}\text { Pre-Quota Only } \\
\text { (2) } \\
\end{array}$ & $\begin{array}{l}\text { Pre- and Post- Quota } \\
\text { (3) }\end{array}$ & $\begin{array}{c}\text { Pre-Quota Only } \\
(4) \\
\end{array}$ & $\begin{array}{l}\text { Pre- and Post- Quota } \\
(5)\end{array}$ & $\begin{array}{c}\text { Pre-Quota Only } \\
(6) \\
\end{array}$ \\
\hline Proportion of type 3 & $\begin{array}{c}-0.00263 \\
(.0156)\end{array}$ & $\begin{array}{c}-.0796 * * * \\
(.018)\end{array}$ & $\begin{array}{l}0.00721 \\
(.0124)\end{array}$ & $\begin{array}{l}-0.0124 \\
(.0145)\end{array}$ & $\begin{array}{c}-.0273 * * * \\
(.00943)\end{array}$ & $\begin{array}{c}-.0403 * * * \\
(.00993)\end{array}$ \\
\hline Proportion of type 4 & $\begin{array}{l}.0456^{* * *} \\
(.0153)\end{array}$ & $\begin{array}{l}.0312^{*} \\
(.0173)\end{array}$ & $\begin{array}{l}-0.0131 \\
(.0121)\end{array}$ & $\begin{array}{l}0.00716 \\
(.0134)\end{array}$ & $\begin{array}{l}.0189 * * \\
(.00892)\end{array}$ & $\begin{array}{l}.0215^{* *} \\
(.0093)\end{array}$ \\
\hline Proportion of type 5 & $\begin{array}{l}0.0102 \\
(.0147)\end{array}$ & $\begin{array}{l}.0518^{* * *} \\
(.0162)\end{array}$ & $\begin{array}{l}-0.00826 \\
(.0109)\end{array}$ & $\begin{array}{c}-0.01010 \\
(.0119)\end{array}$ & $\begin{array}{l}-0.00209 \\
(.00818)\end{array}$ & $\begin{array}{l}0.00383 \\
(.00861)\end{array}$ \\
\hline Proportion of type 6 & $\begin{array}{c}-.061 * * * \\
(.0123)\end{array}$ & $\begin{array}{l}-0.0111 \\
(.0125)\end{array}$ & $\begin{array}{l}.0204 * \\
(.0114)\end{array}$ & $\begin{array}{l}.0206^{*} \\
(.0119)\end{array}$ & $\begin{array}{c}.0155^{*} \\
(.00914)\end{array}$ & $\begin{array}{l}.0207 * * \\
(.00891)\end{array}$ \\
\hline Observations & 71713 & 63232 & 53008 & 45887 & 113985 & 107194 \\
\hline
\end{tabular}

${ }^{\mathrm{a}}$ The regression equation is $y_{\mathrm{bk}}=\alpha+\beta Q C_{b k t}+\Sigma_{l=1}^{4} \varphi_{l}\left(\text { percent } C_{b k}-0.87\right)^{l}+\varepsilon_{b k t}$ where $y_{\mathrm{bk}}$ is the outcome variable (proportion type 3, proportion type 4, proportion type 5, proportion type 6 units in each block $b$, town $k ; Q C_{b k t}$ is a dummy that is 1 if the Chinese quota is binding in month $t$; (percent $\left.C_{b k}-0.87\right)^{l}$ are $l^{\text {th }}$ order polynomials of percent Chinese, centered around the block quota cutoff. I repeat the exercise for the Malay quota and for the Indian quota. Columns 1 , 3 and 5 report results using all blocks that are within 10\% of the Chinese, Malay, and Indian quota cutoffs, respectively. Columns 2, 4 and 6 report results using only the blocks that were built before the policy started in1989. Standard errors are in parentheses and clustered at the block level. ***Statistically significant at $1 \%$. $* *$ Statistically significant at $5 \%$. Statistically significant at $10 \%$. 


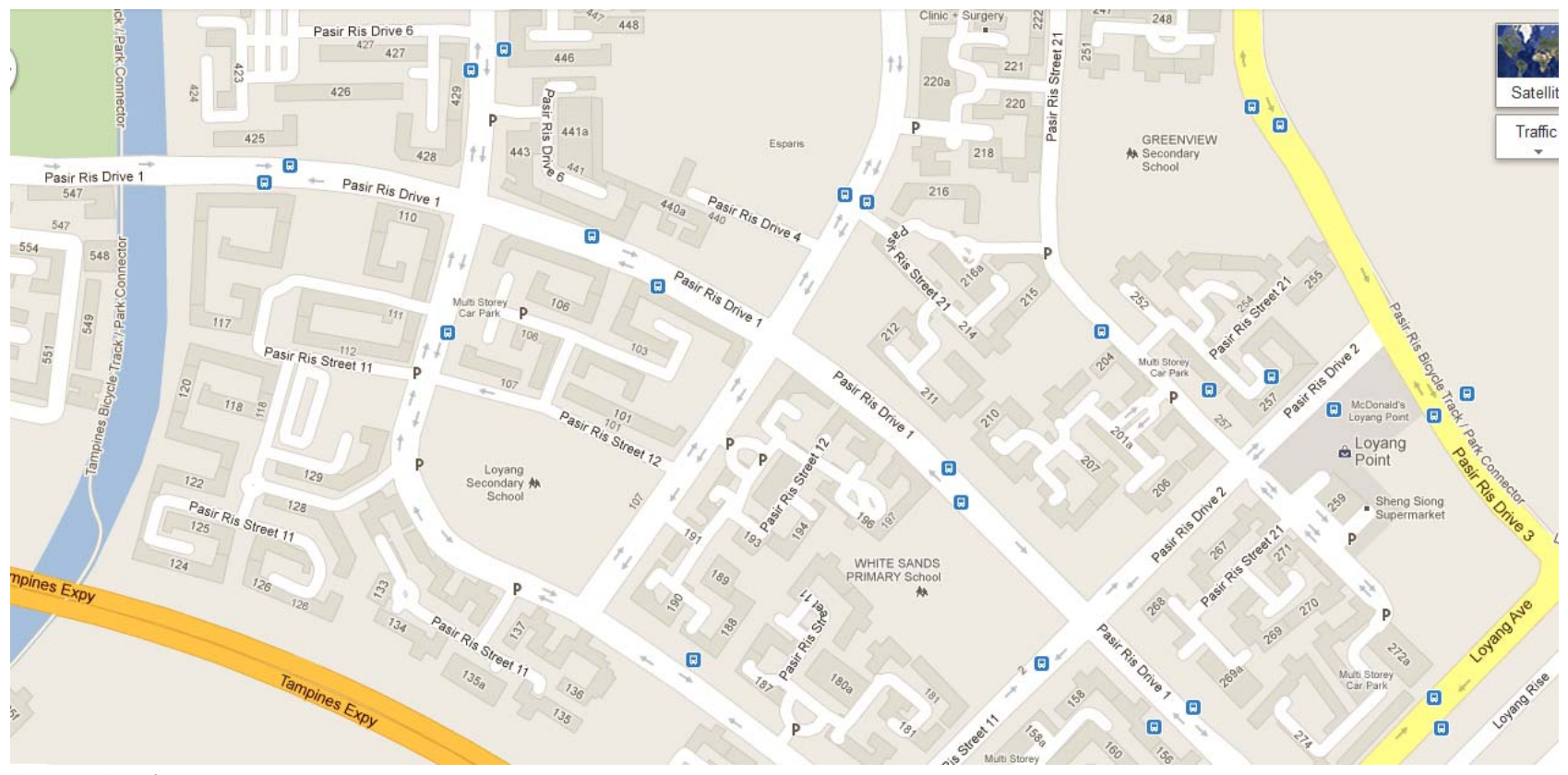

Source: Google Maps

FIG. 1. - Map of HDB blocks and HDB neighborhoods. Each number in the map corresponds to an HDB block. There are 4 HDB neighborhoods in this map. Neighborhood 1 comprises all HDB blocks between 100 and 199, neighborhood 2 comprises all HDB blocks between 200 and 299, neighborhoods 4 and 5 are defined in a similar manner. 
a. The Impact of Chinese Block Quotas on $\ln ($ price $)$

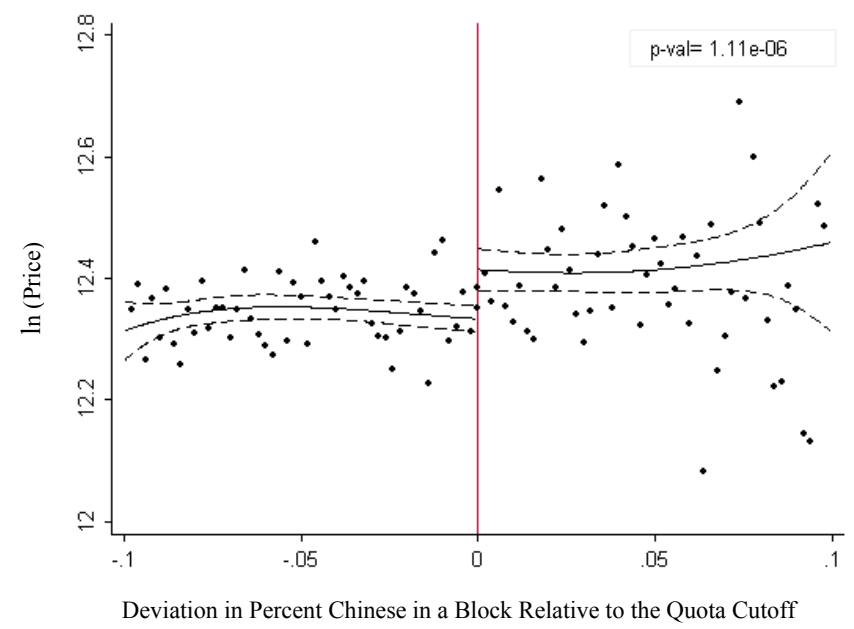

b. The Impact of Malay Block Quotas on $\ln ($ price $)$

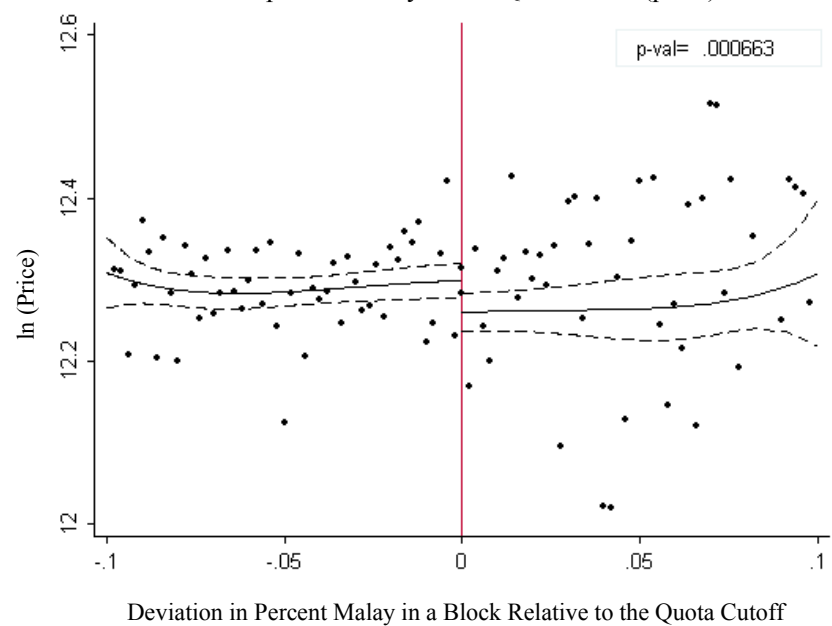

c. The Impact of Indian Block Quotas on $\ln ($ price $)$

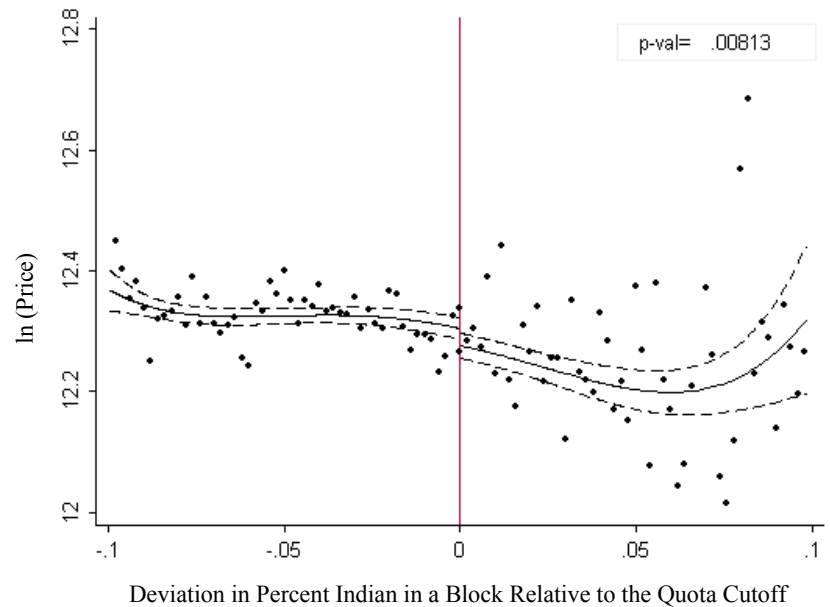

Fig. 2. Impact of block quotas on InPrice, $10 \%$ above and below the quota cutoffs. Each panel in this figure is constructed using the following procedure for observations within $10 \%$ of the ethnic quota cutoffs: (i) regress the log of transaction prices on smooth functions of ethnic proportions centered around the quota cutoffs (4th order polynomials) and a dummy that is 1 when the corresponding block quota is binding in the previous month; (ii) plot the predicted prices (solid line) as well as the $95 \%$ confidence interval (dashed lines); (iii) plot means of $\ln$ (price) for each $1 \%$ bin. I repeat the exercise for the Malay quotas and Indian quotas. Standard errors clustered at the block level. Reported p-values correspond to the hypothesis test that the discontinuity at the cutoff is 0 . The coefficient estimates are $8.1 \%,-3.96 \%$ and $-2.85 \%$ for the Chinese, Malay and Indian quotas. 
a. Probability that the Chinese Quota Binds

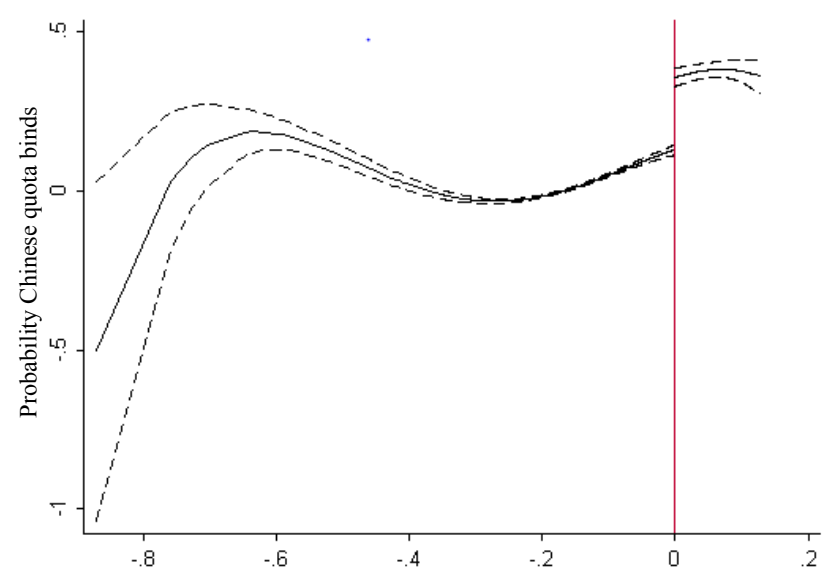

Deviation in Percent Chinese in a Block Relative to the Quota Cutoff

b. Probability that the Malay Quota Binds

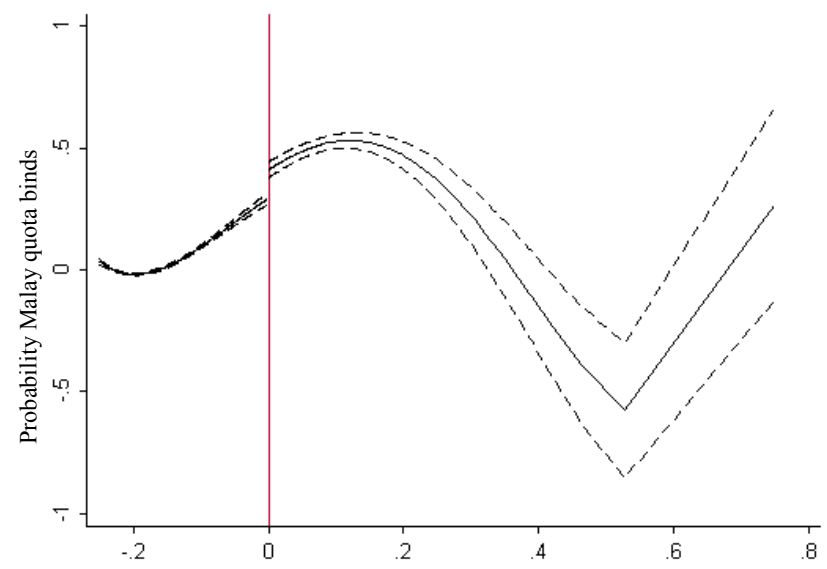

Deviation in Percent Malay in a Block Relative to the Quota Cutoff

c. Probability that the Indian Quota Binds

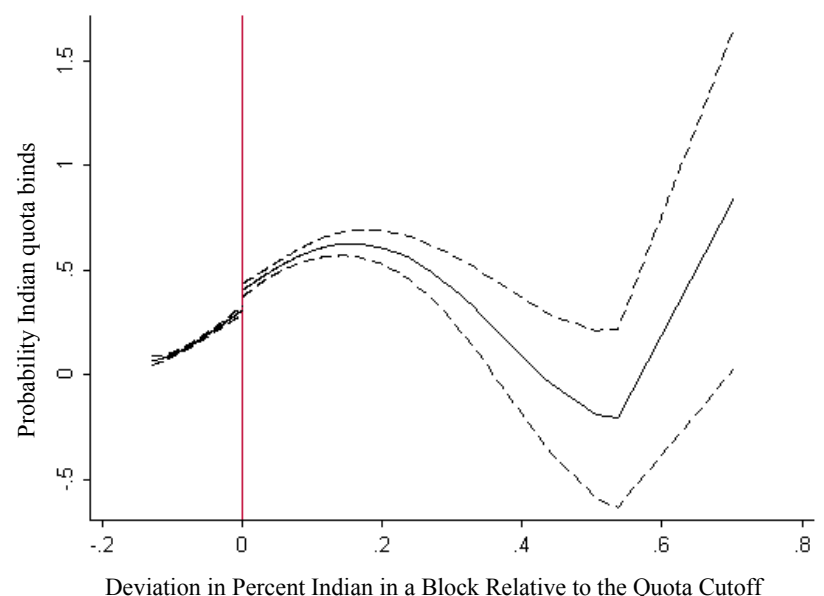

Fig. 3. Testing for discontinuity in the probability that the quota binds. Each panel in this figure is constructed by regressing $Q_{\mathrm{bt}}$ ( $a$ dummy for whether the quota is binding for block $b$ in month $t$ ) on a dummy that is 1 when the ethnic proportions are above the block quota cutoff and 4th order polynomials of ethnic proportions, centered around the quota cutoffs, then plotting the predicted probabilities. Repeat the exercise for the Malay quotas and Indian quotas. The dashed lines represent $95 \%$ confidence intervals. Standard errors clustered at the block level. The coefficient estimates are $23 \%, 12 \%$ and $10 \%$ for Chinese, Malay and Indian quotas. 
a. Density of percent of Chinese in a block

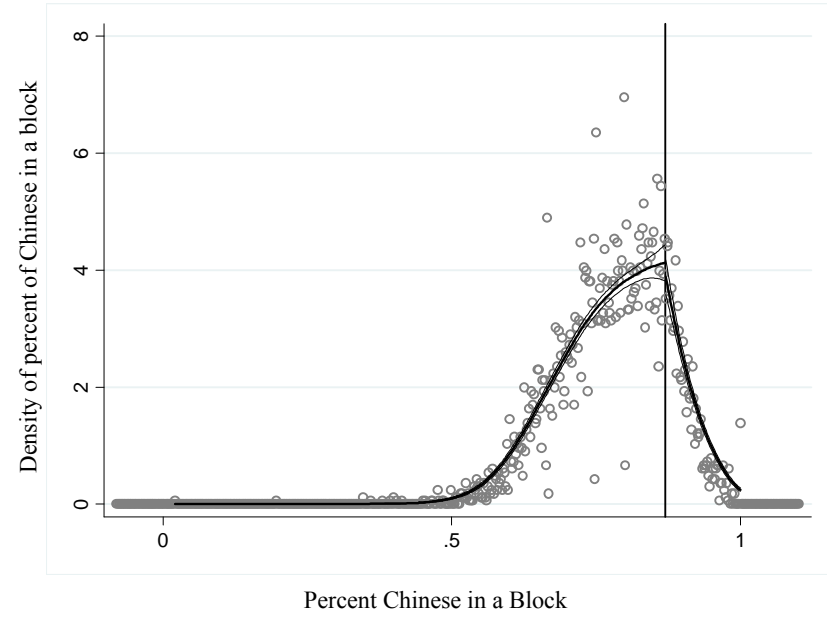

b. Density of percent of Malays in a block

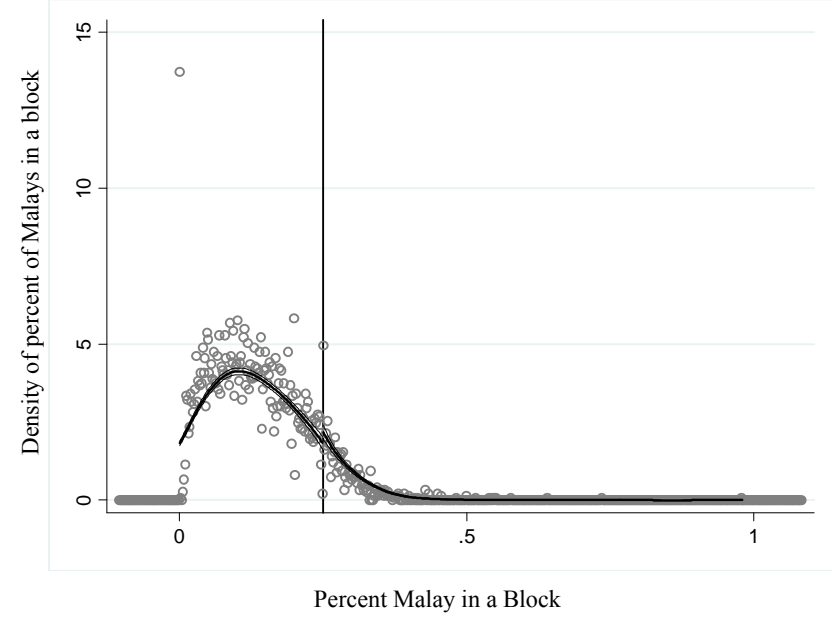

c. Density of percent of Indians in a block

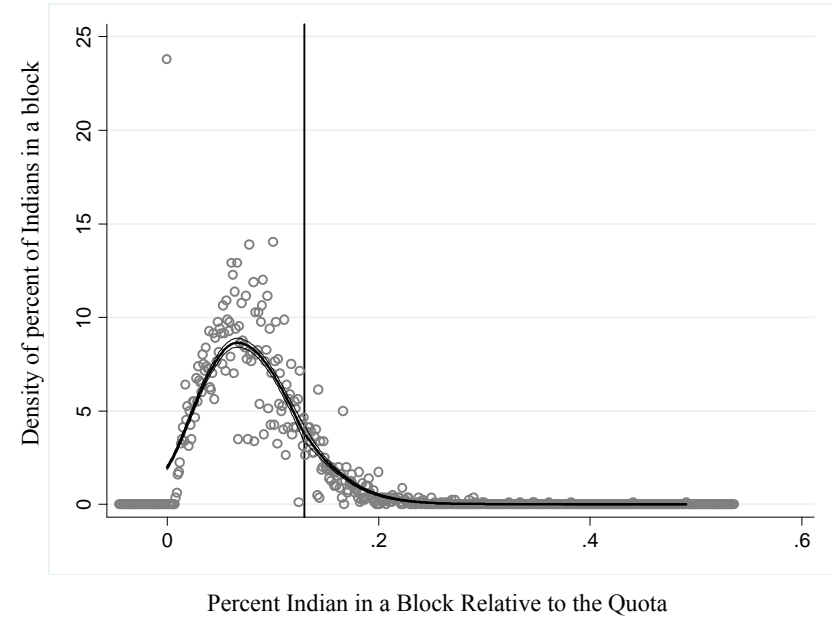

Fig. 4. Testing for discontinuities in the density of the running variable (ethnic proportions). The vertical lines correspond to the quota cutoffs. 